\title{
Dietary triggers in irritable bowel syndrome
}

\author{
Allan D. Shaw, Jillian L. Brooks, John W.T. Dickerson and G. Jill Davies \\ Nutrition Research Centre, School of Applied Science, South Bank University, \\ 103 Borough Road, London SEI OAA
}

\begin{abstract}
Irritable bowel syndrome (IBS) is a frequently occurring, benign functional gastrointestinal disorder with a complex poorly understood pathology which appears to be multifactorial in nature. There is no association with structural or biochemical abnormalities in the gastrointestinal tract. Functional variations in myoelectrical activity, visceral hypersensitivity and illness behaviours have all been observed in patients experimentally. In conjunction with environmental, psychological and alimentary factors, these mechanisms have been proposed as the major determinants of symptom genesis. Certainly, dietary factors are frequently perceived by sufferers as powerful symptom triggers, with many reporting multiple food intolerance. Physicians, however, remain divided upon the relevance of food to the disorder, with many eschewing a nutritional connection. This is unsurprising as, despite much experimental work to determine the clinical relevance of food intolerance and allergy to the aetiology of the disorder, the vast range of foodstuffs available for testing, inherent procedural problems with test foods, methodological insufficiencies and the continually evolving knowledge of the disorder, particularly the subgrouping of sufferers, have restricted the scientific validity of current findings. At the present time, it is difficult to make informed judgement upon the importance of food in IBS, and rigorously designed, large scale trials devised in the light of recent knowledge are required before conclusions can be drawn.
\end{abstract}

\section{Introduction}

Irritable bowel syndrome (IBS) is a frequently occurring yet poorly understood benign gastrointestinal disorder. IBS exerts a considerable burden upon health resources (Coremans et al. 1995; Houghton et al. 1996), accounting for approximately $10 \%$ of the workload of general practitioners (Jones, 1996) and severely affects health-related quality of life (Whitehead et al. 1996). Historically, a variety of terms have been used to describe the condition, including 'membranous enteritis' (DaCosta, 1871), 'neurogenic mucous colitis' (Bockus et al. 1928), 'Spastic Colon' (Chaudhury \& Truelove, 1962), and 'Irritable Colon Syndrome' (Wangel \& Deller, 1965). These are now thought to be inadequate (Dotevall, 1985a). In addition, the generic terms 'Functional Colonic Disorder' (Debry \& Drouin, 1976), 'Functional Gastrointestinal Disorder' (Ferguson et al. 1977), 'Functional Bowel Disorder' (FBD) (Thompson \& Heaton, 1980), and 'Functional Abdominal Complaint' (Van Dulmen et al. 1997) have all been 
used to connote syndromes characterized by the absence of detectable structural or biochemical abnormality within the gastrointestinal tract (Thompson et al. 1989). A recent paper by Bennett et al. (1998) classifies IBS as a heterogeneous group of syndromes, rather than a single disease entity. A genetic component has also been proposed (Morris-Yates et al. 1998). There are no known associations with organic diseases (Fry, 1985), although such concerns are cited by as many as 50\% of sufferers (Fielding, 1977a; Paulley, 1984). Research diagnoses made using symptom based criteria (Tables 1 \& 2) have all specified abdominal pain and disturbed defaecation in the absence of organic bowel disease (Manning et al. 1978; Thompson et al. 1989, 1992), though such criteria are infrequently used in primary care (Thompson et al. 1997) and have recently been criticized for lack of specificity (Coxe, 1998).

The estimated prevalence of IBS is $5-19 \%$ in men and 14-24\% in women (Drossman et al. 1997), though only a minority ever consult a doctor (Jones, 1996; Hahn et al. 1997). Symptoms characteristically relapse and remiss (Misra et al., 1989; Talley et al. 1992) and, inherent in the nature of a syndrome, clinical manifestations vary widely. There is no single pathological mechanism, and a multifactorial aetiology has been proposed. Abdominal pain is the most common gastrointestinal symptom, epidemiological study suggesting that between 57 and 100\% of patients (Maxton et al. 1989; Barbara et al. 1991; Everhart \& Renault, 1991) are affected. With no consensus regarding diagnosis, continually evolving knowledge of subgroups (Drossman et al. 1977, 1990; Talley et al. 1995b), and the myriad studies conducted before development of diagnostic criteria, study populations are often heterogeneous, rendering interstudy comparison limited. This is further compounded by varied interpretation of diagnostic terms such as 'constipation' and 'diarrhoea', which remain central despite their inexactitude. The major perceived symptom triggers are diet and stress, and their involvement in the aetiology of IBS is supported by epidemiological evidence (Friedman, 1991; Phillips et al. 1992; Thompson, 1993). In developing countries, IBS is more prevalent in industrialized communities with greater stress levels and more refined diets than their rural counterparts (Segal \& Hunt, 1975; Segal \& Walker, 1984).

Clinically significant psychiatric disturbance is associated with the syndrome, and dramatically affects quality of life (Patrick et al. 1998), although its aetiological significance remains unclear. A role in symptom genesis has been hypothesized (Latimer et al. 1981; Creed, 1994), as has a modulating effect on symptom perception and subsequent illness behaviour (Whitehead et al. 1982; Sandler et al. 1984; Chang, 1996), though such factors have been poorly investigated (Read, 1994; Verhaak, 1995; Zonderman et al. 1985). Causality is blurred due to the mutual reinforcement of physiological and psychological factors (Thompson \& Gick, 1996; Zaubler \& Katon, 1996). While the condition undoubtedly imposes a psychological burden on the sufferer, psychiatric disorder as a response (Kumar et al. 1990; Song et al. 1993) has been largely dismissed as the primary role, as other disorders which inflict chronic pain do not exhibit such a degree of psychological dysfunction (Ryan et al. 1983; Walker et al. 1990; Woodman et al. 1998). In addition to a specific effect in some patients, psychiatric conditions

Table 1. Diagnostic criteria for irritable bowel syndrome (Manning et al. 1978)

1. Pain eased after bowel movement.

2. Visible distention.

3. Looser stools at onset of pain.

4. More frequent bowel movements at onset of pain.

5. A feeling of incomplete emptying.

6. Mucus per rectum. 
Table 2. 'Rome' diagnostic criteria for irritable bowel syndrome (Thompson et al. 1992)

At least three months continuous or recurrent symptoms of:

1. Abdominal pain or discomfort which is:

(a) relieved with defaecation

(b) and/or associated with a change in frequency of stool

(c) and/or associated with a change in consistency of stool

and

2. Two or more of the following, at least a quarter of occasions or days;

(a) altered stool frequency*

(b) altered stool form (lumpy/hard or loose/watery)

(c) altered stool passage (straining, urgency, or feeling of incomplete evacuation)

(d) passage of mucus

(e) bloating or feeling of abdominal distention

- for research purposes, 'altered' may be defined as $>3$ bowel movements/day or $<3$ bowel movements/week.

impinge upon the role of both food and life stress as symptom triggers, though whether psychiatric disorder acts as a direct trigger in a similar way remains unclear. Fowlie et al. (1992) suggested that depression may be involved in the maintenance of daily symptoms, while anxiety disorders were more predictive of long term outcomes. Longstreth \& Wolde-Tsadek (1993), however, reported many psychosocial correlates with symptoms, and Lovibond \& Lovibond (1995) remarked that "considered as an affective or emotional state, the concept of a stress response has clear affinities with anxiety'.

In this review, the nature of the causal relationship between dietary factors and IBS will be examined in aetiological and pathological terms, including the putative interaction with stress, itself another major trigger factor in IBS. The scope of food and drink as primary and secondary symptom triggers can in this way be assessed. Current, symptom-based diagnoses merely indicate the source of irritation, and do not address issues of causality (Read, 1990). Elucidation of trigger factors in this way may lead to more rational diagnosis of IBS.

\section{Physiological sensitivity to foodstufís}

Food sensitivity is a nonspecific term encompassing food intolerance, a reproducible, unpleasant reaction to a foodstuff (Gertner \& Powell-Tuck, 1994), sometimes described as 'idiosyncratic' (World Health Organization, 1987), and specific food allergy where there is a distinct immunologic reaction or anaphylaxis (Millstone, 1997). Such reactions may be immediate or delayed, occurring perhaps days after ingestion of the offending foodstuff. Such a delay invariably complicates the diagnostic process and the identification of cause and effect relationships, particularly as subsequent meals may additionally contain the same or another allergen (Birtwhistle, 1983). Food aversion of psychological origin is also an accepted phenomenon (Royal College of Physicians, 1984; Bindslev-Jensen, 1998) and emphasizes the close association between somatic and psychic features. Historically, the concepts of food intolerance and psychosomatic aversion, like that of delayed hypersensitivity, have few roots, and are relatively recent advancements (Bindslev-Jensen, 1998). Many studies exploring the concept of 
food as a trigger in IBS have thus lacked the opportunity to explore these more subtle features. Nonallergenic results may thus have been interpreted as 'false negatives'. The nature of the problem from the point of view of the often ill-informed medical profession is encapsulated by Truswell (1985), who describes food sensitivity as existing at the 'interface between scientific immunology, food technology, and quackery'.

There is evidence that the incidence of food sensitivity has been steadily rising since the second world war (Ninan \& Russell, 1992), and as such not only the significance of intolerance and allergy per se, but also their impingement upon gastrointestinal disease, which by its nature is often inherently associated with food, is likely to increase in medical and public health importance.

\section{Food intolerance}

\section{Biological factors}

Data pertaining to food intolerance are conflicting. While some workers have concluded that food intolerance is a major factor in the pathogenesis of IBS, responsible for up to $50 \%$ of refractory cases (Hunter, 1998), others have suggested a limited role. The standard method for investigation is the exclusion diet (Parker et al. 1995). Without retesting and challenging this, and if possible double-blind challenge, such an approach is of limited value as psychosomatic placebo responses cannot be distinguished. Nanda et al. (1989) reported improvement in 91 of 189 patients with refractory IBS who followed an exclusion diet for three weeks (Table 3 ). When foods were reintroduced, 72 of the 91 were able to identify food(s) that triggered gastrointestinal symptoms. Only in this subset can it be stated that the exclusion diet was the source of symptomatic relief. Twelve patients remained symptom free even after the reintroduction of their normal diet, emphasizing the need for caution when assigning causality. With no biochemical marker or double-blind challenge, the subjective evidence of the patient determines whether the diet is deemed successful. This is a problem since there may be a psychosomatic component to the remission of symptoms (Pearson, 1986), particularly given the high placebo response common in IBS trials (Cann et al. 1984; Lucey et al. 1987). In addition, the average age of the study population was slightly higher than the median value for IBS (Fielding et al. 1977a) and there was a large female sex bias in the gender structure. A more rigorously defined study group may have yielded more appropriate results.

It must also be borne in mind that Nanda and colleagues (1989) conducted their work before the establishment of the now uniformly accepted guidelines for the diagnosis of IBS (Thompson et al. 1992). As such, it is difficult to have confidence that the populations being studied were actually specific IBS patients, rather than a more heterogeneous bowel disorder group comprising difficult cases labelled as IBS by default through diagnosis by exclusion. Hawthorne et al. (1991), for example, examined 38 refractory IBS patients, of whom 18 improved 'dramatically' on an exclusion diet, of which 16 identified specific foods that triggered symptoms. Sufferers with the 'painless diarrhoea' variant of the syndrome were included, however, and there is now some debate as to whether such cases should be classed as IBS (Spiller, 1994; Camilleri \& Choi, 1997). Thus the results obtained by Hawthorne and colleagues may not be directly comparable with those of other workers, and the opportunity to test food intolerance in a rigidly defined IBS population missed, particularly in the light of Thompson's assertion that the IBS subgroup affected by food intolerance may be the same group that experiences painless diarrhoea, with the majority of pain-predominant sufferers remaining unaffected (1989). It would be wise to view the results of a large proportion of the 


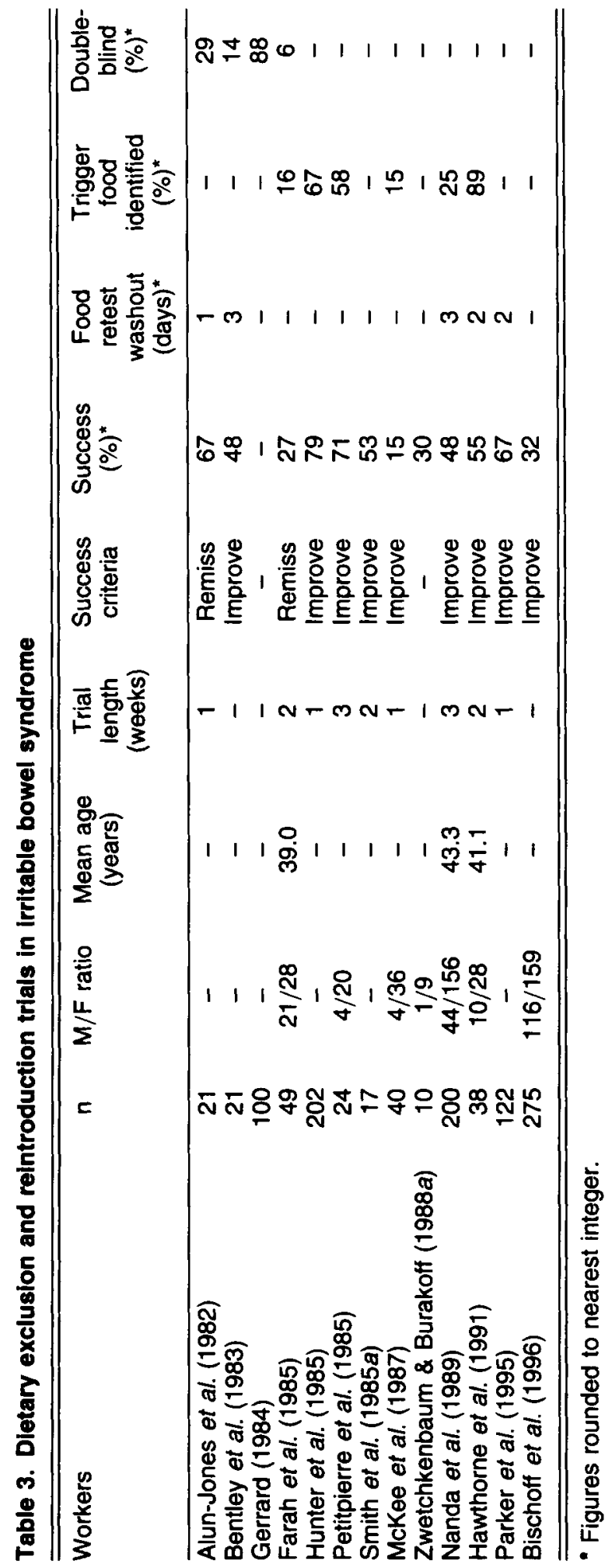


trials conducted on food intolerance in IBS patients cautiously. In none of the three post 1989 studies reviewed here (Table 3 ) was double-blind challenge conducted, and in each case the authors required only symptomatic improvement, not remission, and so an opportunity to substantiate the preliminary observations of other trials has been missed.

\section{Elimination diets and double-blind trials}

Consistent with diagnosis of IBS, there is an absence of biochemical abnormality to identify the intolerant reaction. Alun-Jones et al. (1982) found no significant differences in plasma glucose, histamine, haematocrit, eosinophil count, 'circulating immune complexes' or hydrogen production in volunteers between test and control days. In view of the era in which the study was conducted, it is unlikely that specific antibody deduction tests were performed, and therefore the biochemical data are limited in value. This is particularly so when the lack of demographic information provided about the population is considered, together with the short length of the trial period (Table 3). A double-blind approach is the only practical way to identify food intolerance positively. Using this approach eliminates placebo responses or psychosomatic effects. The relative number of intolerant patients confirmed using such methods is considerably lower than is first apparent from exclusion and reintroduction studies.

Bentley et al. (1983) found consistent exacerbation of symptoms with specific foods on post exclusion retest in 10 out of 21 IBS patients. Eight undertook a double-blind challenge, which confirmed hypersensitivity in three. Each of the other five patients all exhibited multiple placebo responses, highlighting the importance of double-blind studies. With no basic demographic information regarding the study population, and no description of the trial duration, the results obtained must be viewed extremely cautiously, particularly when the lax criteria required for exclusion to have been judged successful are considered (Table 3). Eighty-six percent of the patients had a minor psychiatric disorder, although it is unclear how many were food intolerant. The existence of such disorders may facilitate psychosomatic food aversion and account for cases of food intolerance that are not confirmed by double-blind food challenge.

One study to have reported a considerable improvement rate in double-blind food challenge trials $(88 \%)$ was that conducted by Gerrard (1984). Despite the inclusion of a considerable number of patients $(n=100)$, the lack of demographic information, details about trial length and success criteria, and the fact that the trial was performed prior to the gold standard 'Rome' criteria for diagnosis of IBS (Thompson et al. 1989) render the results of the trial largely inadmissible to the debate.

Farah et al. (1985) found that only 13 of 49 patients became symptom free on a 'low allergenicity' diet. When confronted with double-blind challenge, three identified the provoking agent, while in five the suspected food could not be confirmed as provocative. Therefore in around $6 \%$ only could food be confirmed as the cause of symptoms. This may be due to the low dose used in the challenge $(3.6 \mathrm{~g} / \mathrm{d})$, as food intolerance reactions may be dose dependent. Less conservative results may have been obtained with a greater load. Farah and coworkers employed one of the most rigorous study protocols applied in exclusion trial work and selected an IBS population well balanced in gender terms and of an appropriate age (Fielding, 1977a), so the fact that their results were relatively unconvincing suggests that food intolerance may be relevant to only a specific subset of IBS sufferers.

The outcome of exclusion trials may be affected by the length of the trial period. Smith and colleagues (1985a) investigated 28 IBS patients, who consumed an exclusion diet for either 1 or 2 weeks. Of the former, $18 \%$ showed improvement. In contrast, $53 \%$ of those following the diet for 2 weeks improved. The improved response at 2 weeks, sustained over 1 year in 7 patients, suggests genuine rather than placebo effects. The authenticity of shorter trials has been con- 
firmed, however, using double-blind studies (Alun-Jones et al. 1982). Commensurate with the results of others (McKee et al. 1987; Hawthorne et al. 1991), a better response was observed in patients with predominant diarrhoea than those with constipation.

The improvement in diarrhoeal patients compared with constipation patients also becomes more marked over time. When Smith and coworkers (1985b) gave their 28 IBS patients an exclusion regimen, over 2 or 4 weeks, little improvement occurred in the 2 week study. On the 4 week regimen, two thirds of diarrhoeal subjects improved, compared with only one fifth of constipated patients. Irrespective of the diagnostic subgrouping, however, even the 4-week test period is insufficient for proper determination of the effect of an elimination diet, and a longer trial is required to confirm these preliminary findings. When improved subjects were considered together, $78 \%$ sustained improvement over the following 12 months. Long term improvement has been noted by several groups (Table 4), confirming the therapeutic benefit of dietary regimens.

Similar problematic foods have been reported in subjects without IBS (Lessof et al. 1980; Egger et al. 1983), and within IBS there is consistency across trials (Table 5), such that Parker et al. (1995) found the results of trials performed using nutritionally adequate exclusion diets to be comparable with those using a more rigid regimen. While such identification cannot distinguish placebo responses, the emergence of particular foodstuffs as gastrointestinal antagonists warrants further investigation, particularly as many staples of the diet are thus perceived. The prevalence of multiple intolerance is also remarkable. Hunter et al. (1985) reported that $15 \%$ of their patients were intolerant to more than 20 foods. There is some suggestion, however, that patients may not always correctly identify the provocative food. In trials where the open reintroduction of foods is not sufficiently spaced, and where biochemical confirmation is not sought, reactions to foods may be misinterpreted. Response may not occur immediately following the challenge (Alun-Jones et al. 1983). Tolerance to foodstuffs may be regained during abstinence of only $17 \mathrm{~d}$, and a provocative food challenge may lower the threshold of tolerance to other foods, including those previously tolerated (Birtwhistle, 1983).

\section{Underlying pathology}

The corollary to the identification of foodstuffs as triggers is determination of the underlying pathological mechanisms. Alun-Jones et al. (1982) measured rectal prostaglandin ( $\left.\mathrm{PGE}_{2}\right)$ in food intolerant IBS cases. Levels, low basally and after control meals, rose significantly after test meals. Production of $\mathrm{PGE}_{2}$ was significantly associated with increased daily faecal wet

Table 4. Percentage of patients symptom free on long term exclusion diets

\begin{tabular}{lrcc}
\hline \hline Source & $n$ & $\begin{array}{l}\text { Follow-up range } \\
\text { (months) }\end{array}$ & \% Symptom tree* \\
\hline Hunter (1985) & 71 & $2-20$ & 100 \\
Hunter (1985) & 41 & $2-16$ & 100 \\
Hunter (1985) & 61 & $22-39$ & 87 \\
Farah et al. (1985) & 5 & $6-18$ & 80 \\
Smith et al. (1985a) & 9 & 12 & 78 \\
Nanda et al. (1989) & 73 & $14.7^{\star *}$ & 99 \\
\hline
\end{tabular}

* Figures rounded to nearest integer.

** Mean. 


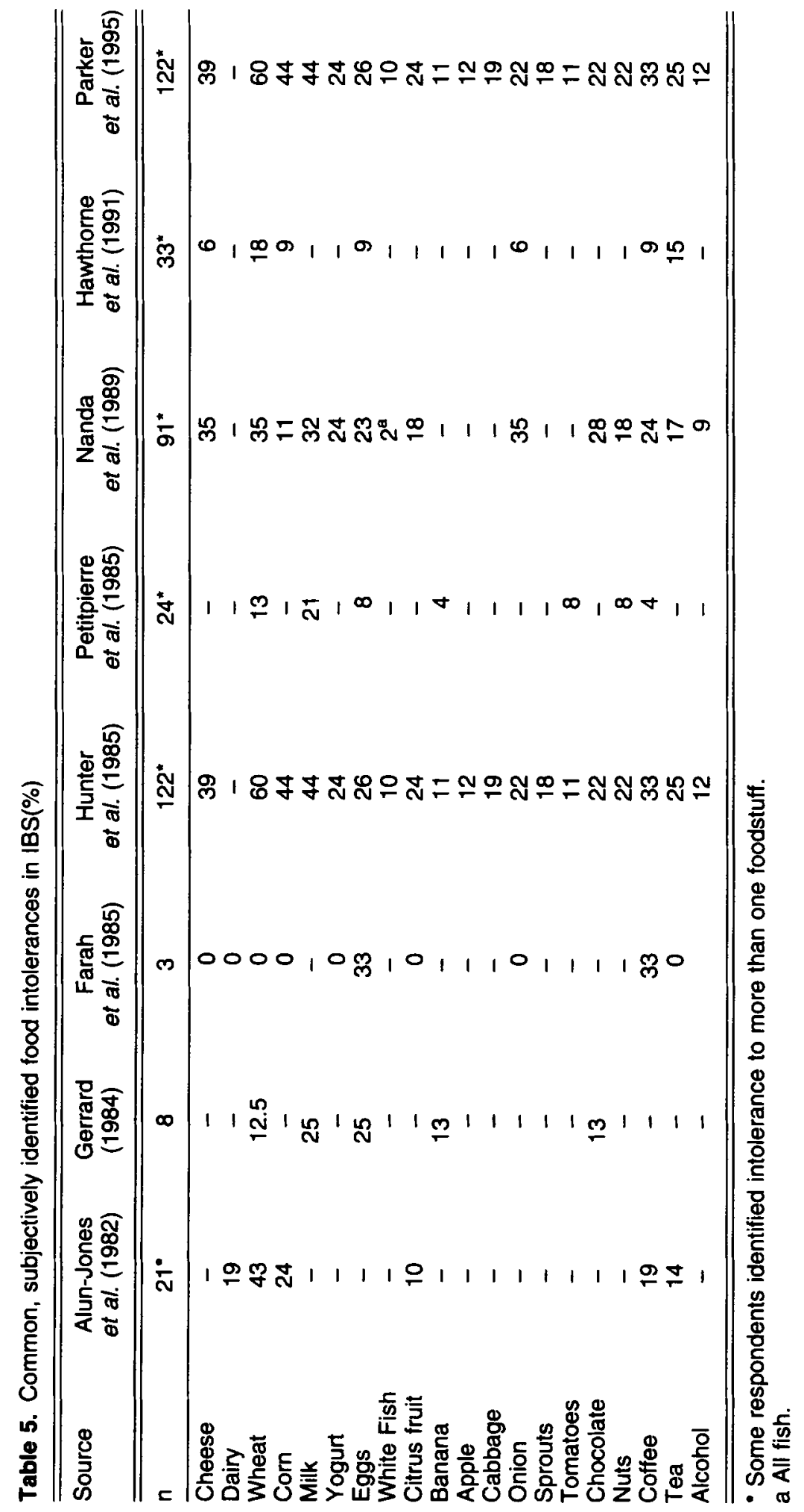


weights $(P<0.01)$. The mechanisms by which ingestion results in prostaglandin production were not examined. It was concluded that the rise in prostaglandin production after ingestion of foods, and subsequent discovery of an association between prostaglandins and faecal weights, provides some evidence for the role of prostaglandins in the mediation of symptoms.

In a comprehensive study of 202 patients, Hunter \& Alun-Jones (1985) found no increase in immune complexes, eosinophil count, or plasma histamine concentration following doubleblind food challenge. Neither were significant differences found between fasting and postprandial levels of gastrointestinal hormones. Uniformity in basal and postprandial gastric hormone levels in IBS patients was confirmed by other workers (Besterman et al. 1981). Sjölund \& Eckman (1987), however, found both basal and postprandial changes in hormone profiles when the IBS population was divided into symptom subgroups. Similarly, Bearcroft $e t$ al. (1998) found altered postprandial release of 5-hydroxytryptamine in diarrhoea predominant IBS patients compared to normals. Given the association of food induced symptoms in diarrhoeal patients, further investigation is justified.

Investigation of faecal flora revealed high numbers of anaerobes in two thirds of subjects, with a large increase after food challenge (Hunter \& Alun-Jones, 1985). The conclusion that food intolerance reflects altered metabolism of foods by intestinal microflora must be viewed as a preliminary finding, given that the population were not necessarily IBS patients. A later study by Balsari et al. (1992) confirmed the presence of increased numbers of facultative anaerobes in the faeces of patients with IBS, considerably substantiating the claim that food intolerance in IBS patients is due to malfermentation of food in the colon by an atypical bacterial load (Hunter, 1991). Rapid colonic fermentation by such bacteria has been shown to be associated with symptom development in IBS, and corrected by imposition of an exclusion regimen (King et al. 1997). Bradley and coworkers (1987) identified large numbers of facultative bacteria in the faecal sample of a single patient with multiple food intolerance, while Wyatt et al. (1988) refined the method, studying floral changes between periods with and without untolerated food. Differences in faecal output, flora and short chain fatty acid content were observed, although only two patients were investigated, so the results cannot be held as conclusive for the population at large.

Altered metabolism of unabsorbable carbohydrates and short chain fatty acid (SCFA) production in IBS was observed by Treem et al. (1996). IBS patients had less total SCFA, proportionately less acetate $(P<0.05)$, and more n-butyrate $(P<0.05)$ than controls. SCFA are associated with the absorption of electrolytes and water, and colonic mechanisms of diarrhoea (Mortensen \& Clausen, 1996). Differences in SCFA production by colonic bacterial flora in IBS may therefore be related to diarrhoeal symptoms. In the light of these findings, therapy directed at alteration of the host bowel flora has been advocated as a treatment for IBS (McEvoy, 1989).

Currently, much of the evidence for food intolerance or allergy as a trigger for symptoms of IBS is based on subjective identification of untolerated foods. These results must be considered in the context of the prevalence of both IBS and food intolerance in the community. Both occur in approximately one fifth of the population, and so a degree of noncausal coexistence is inevitable (Young et al. 1994; Farthing, 1995). Few studies have confirmed subjective causality with double-blind challenge (Table 3 ), and many describe improvement, rather than remission of symptoms when suspected foods are eliminated. In addition, the length of trial period is minimal in many studies (Table 3). Even in trials using the relatively lengthy 4 week duration, assessment of the efficacy of dietary regimens is unlikely to prove conclusive. Surprisingly, many workers do not even provide details of this crucial parameter. When coupled with the paucity of data pertaining to immunogeneity following food challenge, 
it can only be concluded that the true effects of food intolerance upon gastrointestinal function have been poorly documented, and further investigation encompassing modern research methods is required before conclusive comment can be made. Undoubtedly, it is the inconclusive nature of the research to date that persuades Thompson (1993) against food intolerance. In the light of the methodological problems highlighted in this review, however, it would seem that this view may be excessively strong given the weight of current evidence. The same is true, however, of the diametrically opposing view. Painter (1972) suggested that the evidence for disruption of the bowel by dietary constituents was so strong that it would be more pertinent to refer to the 'irritated', rather than the 'irritable' bowel, the latter implying an inherent design flaw in the gut construct, rather than a functional problem of processing the gut afferent input.

Food intolerance is associated with neurological, psychological, neuropsychological and neurophysiological symptoms (Egger, 1997). It triggers episodes of IBS and is a cause of gastrointestinal symptoms in a specific subgroup of patients. Results improve with increased trial duration, and diarthoea predominant patients are particularly responsive to exclusion. It is possible the painless diarrhoea subgroup are predominantly affected (Thompson, 1989). In spite of the methodological inadequacies that have dogged the majority of trials, the percentage of patients reported as being symptom free when following long term exclusion diets is remarkable (Table 4). Thus for some patients the therapeutic potential of diet as a management tool is encouraging, as all colonic symptoms are relieved, and a subsequent improved quality of life has been reported (King \& Hunter, 1997). There is little substantive evidence, however, for the underlying pathological basis. Gastrointestinal hormone production and circulation seem not to be affected (Hunter \& Alun-Jones, 1985). Investigation of the metabolism of food by gut bacteria has proved inconclusive. As Thompson (1989) opines: "We need to know more about the effect of food components on the colon".

\section{Food allergy}

Smith et al. (1985b) applied skin prick tests (SPT) for IgE antibodies to 28 IBS patients. Seventeen were identified as atopic, as compared with six controls. The significant difference between the groups $(P<0.01)$ was heralded as evidence that IBS may be a disorder of organic origin, with food hypersensitivity a pathogenic factor. Inclusion of patients with previous history of food-related symptoms, however, may skew the results in favour of identifying a relationship.

Zwetchkenbaum \& Burakoff (1988a) evaluated 10 patients with IBS for food hypersensitivity, using SPT and radio-allergosorbent tests (RAST) to common foods. Subsequent elimination diets were followed by challenge with allergenic foods. Six patients had positive SPT but only one had a significant reaction to RAST. In none, however, did food challenge affect presentation of IBS. The failure of skin pricking and RAST to provide conclusive evidence of hypersensitivity, and the lack of correlation with symptoms is not suggestive of a pathogenic role. The apparent false positive identifications made using SPT substantiate previous criticism of the method as a determinant of allergic reactions (Lessof et al. 1980; Schmidt \& Floch, 1992). In 1983, Alun-Jones et al. wrote in The Lancet that skin prick tests "are of no value in the diagnosis of food intolerance", and later Truswell (1985) decried SPT for the high degree of false positive and false negative results obtained, and the lack of diagnosis of delayed hypersensitivity. RAST was also thought to suffer from high levels of false identification and the fact that it relies on identification of $\operatorname{IgE}$ antibodies in serum, which may persist in people who had childhood allergies but are now able to tolerate the relevant foodstuff. Circulating 
immune complexes have been found in both atopic and nonatopic individuals after food ingestion by several workers (Carini et al. 1987). It is surprising then that almost a decade after the initial criticism, Zwetchkenbaum \& Burakoff (1988a) based their trial on knowingly flawed methods. In addition, the reference they cite as having used to diagnose clinical IBS (Petersdorf et al. 1983) is relatively obscure. The authors state that all of their patients had constipation among other symptoms; this is not itself a diagnostic criterion for IBS, and once again marks out the study population as being a specific symptom subset.

Food allergy appears relevant only to a specific subgroup of those with gastrointestinal complaints. The size of this group is one tenth of the size of that comprising those perceiving any effect of foodstuffs on their gastrointestinal symptoms (Zwetchkenbaum \& Burakoff, $1988 b$ ), although nonallergic food intolerance may account for a proportion of the difference. Considering a heterogeneous bowel disorder group, while not conducive to the drawing of specific conclusions, sets the results obtained in studies of IBS in a wider context, and confirms a role for perceived food intolerance or allergy, a large proportion of which appears to be psychological in origin.

\section{Psychosomatics}

To ascertain the prevalence of a psychosomatic component, Pearson et al. (1983) conducted an exclusion trial in 23 patients with suspected food allergy. None of the four patients in whom hypersensitivity was confirmed had a diagnosable psychiatric disorder. All patients, however, exhibited multiple symptoms. Eleven reported definite reactions to subjectively identified substances, despite absence of immunologic confirmation. All of the patients with unconfirmed hypersensitivity had diagnosable psychiatric illness. The role of psychological factors appears to be 'causal', rather than as a result of food allergy. Somatic presentation accompanying psychological symptoms is well documented (Kirkmayer \& Robbins, 1996). The majority of patients with suspected food hypersensitivity appear to fit this model. These findings were criticized by Rippere (1983), claiming exaggeration of the concomitant psychological factor owing to an inability to distinguish nonimmediate hypersensitivity, or nonimmunologic effects. Though Pearson and coworkers (1983) only sought to identify the magnitude of psychological responses in allergenic patients, it may be of more practical use to assess the psychological response to food sensitivity in general. Rix et al. (1984), however, found no evidence of any psychiatric disturbance in four patients with food allergy confirmed by double-blind provocation. Though the sample size is too small for all but the most preliminary of observations, there appears to be little evidence for a psychological burden attached to food allergy. A more substantial finding related to the nineteen patients (83\%) who believed they had an allergy, which could not then be confirmed by exclusion diet and reintroduction trial nor by double-blind challenge, thus strengthening the case for a psychosomatic basis for a large proportion of putative allergy cases. True allergic cases account for a minority of all cases reported.

Petitpierre et al. (1985) investigated 'food hypersensitivity' as a cause of IBS by exclusion diet and blind provocation. Atopic and nonatopic individuals were challenged with a range of foods and additives. SPT and RAST were conducted in all cases, despite the fact that such tests had previously been denigrated (Lessof et al. 1980). Serum IgE level was also measured. In 14 patients, food(s) or additive(s) induced typical symptoms of IBS. In at least nine cases of atopy, an IgE mediated mechanism was identified. In the nonatopic patients, intestinal presence of yeast such as Candida albicans or Geotrichum candidum seemed to be associated with the 
development of pseudo-allergic reactions. Middleton et al. (1992), however, isolated C. albicans from the stools of only approximately $6 \%$ of IBS patients.

In comparison with a control population, children diagnosed with IBS showed modifications of intestinal permeability in relation to ingestion of specific foods (Barau \& Dupont, 1990). Subjects had either personal and/or familial history of allergy and/or raised total serum IgE. Amelioration of symptoms was achieved either by excluding the offending food alone or in conjunction with disodium cromoglycate. It appears that in some children at least, symptoms of IBS may be related to food hypersensitivity.

The evidence for immunologically mediated symptoms of IBS is unconvincing. While a minority of sufferers may have specific food allergies, true hypersensitivity is unlikely to be a major pathogenic factor in the disorder. Hunter \& Alun-Jones (1985) confirmed a true allergic reaction in only $10 \%$ of patients they examined. Immunologically mediated symptoms question whether atopy contributes to a functional condition. The 'functional' label applied to IBS has been questioned (Smith et al. 1985b), as each of the three hypersensitive patients they identified had a history of atopic diseases; but only one responded positively to SPT after ingestion of the problem food, which confounds the result somewhat.

Bengtsson et al. (1996) suggested that inflammatory mechanisms may be involved in the mediation of atopic symptoms. Thirty-five patients $(60 \%)$ had mucus in their stools, one of the cardinal signs of IBS (Manning et al. 1978), though this was not correlated with atopy. Patients were mostly unable to relate the exposure to certain foods to specific symptoms. However, significant positive correlations were identified between gastrointestinal symptoms and chocolate, vegetable, and meat and mucus in the stools. Forty-one patients reported the immediate onset of gastrointestinal symptoms following ingestion of the relevant food. Twenty of these were atopic according to SPT. Of 11 patients with late onset of symptoms, 10 responded negatively to an SPT $(P<0.05)$.

\section{Physiological sensitivity to food components}

Table 5 shows that intolerance to specific groups of foods appears repeatedly across trials. The two most powerful symptom provoking groups appear to be dairy products and foods of cereal or vegetable origin. The disaccharide sugar present in milk, lactose, and the indigestible fibre fractions of cereal grains and vegetables have both been extensively investigated in terms of their gastrointestinal activity and potential pathogenic role in IBS.

\section{Lactose}

Lactose intolerance is symptomatically indistinguishable from IBS (Enck et al. 1984; Gudmand-Hoyer, 1994; Vernia et al. 1995), and misdiagnosis is common (Bolin et al. 1982; Enck et al. 1990; Vesa et al. 1998). Even the psychological profiles of IBS and lactose intolerant patients, obtained using the Hopkins symptom checklist, are comparable, and significantly elevated from controls (Whitehead et al. 1988). Physically, no significant differences in colonic motility can be found between lactose malabsorbers and IBS patients (Enck et al. 1989). As it is caused by a biochemical abnormality, lactose intolerance is, however, an organic rather than a functional disorder. Acidic stools and breath hydrogen provide reliable markers of altered metabolic processes, which are not apparent in IBS. 
Only half of patients with suspected lactose intolerance improve with lactose free diets (Enck et al. 1984) suggesting either a high degree of misdiagnosis and/or concomitant IBS inflicted by other pathological factors. However, patients were tested for the condition of lactose malabsorption through use of the hydrogen breath test, not intolerance, which can only be confirmed by challenge with lactose-containing foods and may not reveal abnormal breath hydrogen; intolerance cannot necessarily be inferred by successfully confirming malabsorption.

The prevalence of lactase deficiency in IBS mirrors that found in the general population, making it unlikely that intolerance develops subsequent to IBS. Newcomer \& McGill (1983) found equal lactose intolerance in subjects with and without IBS, with a figure approaching $6 \%$ of all subjects.

Lisker et al. (1989) found eight of 12 IBS patients (67\%) to be unable to digest lactose. When challenged with aqueous microbial $\beta$-D-galactosidase, symptoms were independent of enzymic treatment, further supporting a coincidental relationship between hypolactasia and IBS.

Many lactase deficient patients are misdiagnosed with IBS, which may explain why such a high proportion are unaware of the relationship between food intake and their symptoms (Burgio et al. 1984). Vesa et al. (1998) report that although the incidence of lactose maldigestion in IBS is no more common than in the whole population, those with IBS are more likely to report subjective intolerance $(P<0.001)$, suggesting a large psychosomatic component. Remission on lactose free regimens has been reported (Tamm, 1994), but a recent study by Tolliver et al. (1996) showed that when subjects with IBS were made aware of their malabsorption, some generic improvement in symptoms was reported, through rating of abdominal pain, bowel habit, distension, mucus and relief with defaecation did not vary significantly from baseline values. The weight of evidence is therefore suggestive of a coincidental concurrent association in most patients. The clinician should note, however, that Tolliver's group found that awareness of lactose malabsorption provided $79 \%$ of subjects with a greater awareness of the food-symptom association, and should therefore be disclosed at an early juncture where appropriate.

\section{Dietary fibre}

In the context of IBS, dietary fibre is usually discussed in terms of its management potential. It is not within the remit of this article to debate the conflicting evidence that has been presented. A thorough review of methods is available elsewhere (Rees et al. 1994b).

Dietary fibre has been implicated in aetiological terms (Trowell, 1974). Grimes (1976) suggested that refined, fibre depleted diets are conducive to the muscle spasm that occurs in many gastrointestinal diseases. A review of epidemiological data identified an association between fibre depleted diets and the incidence and prevalence of IBS (Achord, 1979). Floch (1988) suggested that this was due to the decreased luminal volume and consequent impairment of intestinal luminal neurologic control. More recently, Francis \& Whorwell (1994) described the initial belief of IBS as a disorder of fibre depletion, and subsequent indiscriminate advocation of high fibre diets, which caused, rather than relieved IBS in many people. More than 90\% of members of the American Gastrointestinal Association advocated bran as the primary treatment for IBS (Mitchell \& Drossman, 1987). Investigations into the intakes of dietary fibre in IBS, however, have consistently reported that both outpatients (Hillman et al. 1982; Jarrett et al. 1994) and self-help group attenders (Rees et al. 1994a) do not consume significantly greater 
amounts of dietary fibre from food sources than either healthy subjects (Hillman et al. 1982) Crohn's disease or ulcerative colitis patients (Bauer et al. 1983). To date, there appears a considerable disparity between clinical prescription and community lifestyle in IBS patients, a problem that physicians need to rapidly address if management strategies are to be symptomatically effective. This may partly reflect the failure of twenty years of widespread advocacy of bran as a 'cure', regardless of the symptom pattern. With evolving knowledge of the subsets of the disorder (Drossman et al. 1990), individual management strategies developed between patient and physician, which may include fibre if constipation is problematic, but not in large doses if abdominal pain exists, appear the most productive way forward. This is still a reactive, symptom based approach to management of the disorder, however, far from the ideal, causal factor driven methods implored by Read almost a decade ago (1990).

\section{Nutritional imbalance}

The scientific assessment of nutrient intake is a complex problem. Several possible methods are available, with varying degrees of (related) intricacy and accuracy. Simple methods include dietary recall, with the patient being questioned by a specialist dietician, and keeping of an unweighed food record diary, where the food types and possibly generic portion sizes are recorded. Both of these methods are unacceptable from a scientific viewpoint, where the only possible method that can be pursued with any degree of accuracy is a weighed, written dietary inventory. Even this is immensely difficult to perform accurately, owing to a combination of factors relating to the difficulty of full time diary keeping and weighing, and the lack of information readily available from some manufacturers regarding the nutrient content of their produce. Not least is the psychosocial problem that the necessity to weigh and record raw ingredients used in the preparation of recipes unconsciously skews subjects towards the preparation of simpler meals which are easier to record. Thus a true record of dietary intake is not necessarily obtained. Humans tend to consume relatively similar diets over time, and pioneering work by Chalmers et al. (1952) showed that a three-day weighed intake record, comprising two week- and one weekend day is a good approximation of the entire week's average consumption.

Using a weighed inventory, Debry \& Drouin (1976) showed that FBD patients were more likely to consume low levels of energy and macronutrients than healthy subjects, the exception being protein consumption in females. As statistical comparison was not performed, the significance of these findings remains unclear. Post illness changes in diet identified a trend towards restriction of total energy intake, particularly with respect to protein and carbohydrate. Seventy-eight percent of patients had modified their diets, many spontaneously, rather than in response to an adverse food reaction. Hochstrasser \& Angst (1996) confirmed that most patients with gastrointestinal disorders were on modified diets, although whether patient or physician initiated was unclear. Members of an IBS self-help group commonly eschewed prescribed regimens to follow self-initiated diets. Although $80 \%$ had been prescribed a high fibre intake, only $10 \%$ of group members were found to be following their physician's advice (Rees et al. 1994a). At a five-year follow up of a group of IBS patients, however, Fowlie and coworkers (1992) reported none as avoiding specific foods, and that only $63 \%$ had modified their fibre intake, despite medical advice to do so.

Non-nutritive additives, rather than dietary macronutrient or fibre content of the diet have been postulated as affecting the development of IBS by Hillman et al. (1982), from records of weighed dietary intake for five-seven days, and stool collection for at least $48 \mathrm{~h}$. In the absence 
of any substantive evidence, however, the assertion was based on the fact that diets were indistinguishable in macronutrient content. Though diets with an excessive fat, protein, carbohydrate or fibre content may serve to augment these responses, 'ordinary' diets do not preclude them. The similarity between bowel habit and stool characteristics between groups does, however, support the assertion that IBS is not solely a disease resulting from dietary fibre depletion. It is not clear if well defined diagnostic criteria were used for patient selection. All but one of the 30 women had the 'spastic colon' variety of the syndrome (Chaudhury \& Truelove, 1962), with predominant abdominal pain. It seems surprising then that no attempt was made to record pain during the study, and consequently this may explain why the IBS group were not found to differ from normal in their gastrointestinal responses. Given the doubtful inclusion criteria and the limited measurements of bowel function and symptoms, no definitive conclusions can be drawn regarding dietary components as pathological factors. The aetiological reference to food additives in this context appears greatly exaggerated.

Gee et al. (1985) compared the nutrient intakes of groups of subjects with either inflammatory bowel disorder $(n=64)$ or FBD $(n=50)$. The nutrient intakes of both groups were found to be either 'marginal' or 'inadequate' (Canada Department of National Health and Welfare, 1973), in a range of macro and micronutrients, notably protein, iron, vitamin $A$ and thiamin. A greater proportion of women in the FBD group had inadequate intakes of one or more nutrients than those in the inflammatory bowel disorder group. Women in the FBD group had surprisingly low energy intakes, averaging $22 \mathrm{kcal} / \mathrm{kg}$, and 18 of the 32 women in the FBD groups had energy intakes below their theoretical basal requirement. Similarly, their protein intakes were low, averaging less than $0.5 \mathrm{~g} / \mathrm{kg}$ body weight. Women in both groups were found to consume less meat than the general population, and the authors suggest increasing meat intake as a way of boosting energy, protein and micronutrient levels. The major flaw in the study, however, is that the nutrient intakes were obtained by dietary recall, which we have previously discussed as being totally inadequate in scientific terms. It would also have been useful to have a control group of healthy subjects to determine the differences in intake being experienced in the field at the time of the experiment, as the 'Nutrition Canada' figures used for comparison were some 12 years old at the time of the experiment. Gee and colleagues (1985) have certainly identified the requirements necessary to take a detailed inventory of the sufferers of bowel disorders, but a study with less heterogeneous bowel disorder groups, healthy controls and a more rigorous method of nutrient determination is required for the current findings to be substantiated.

Jarrett et al. (1994) measured the food intake of women with $(n=18)$ and without $(n=37)$ FBD using a three-day dietary diary technique. No fundamental differences in intake of energy, fat, protein, total carbohydrate or fibre were observed, though symptomatic women were found to consume more refined carbohydrates $(P<0.05)$. A similar finding was observed by Christensen \& Somers (1995) when comparing the nutrient intakes of 29 depressed and 29 nondepressed otherwise healthy individuals. The depressed individuals consumed significantly more sucrose than the nondepressed individuals $(P<0.5)$. Whether this represents an alimentary as well as a psychological pathway between depressive illness and IBS requires further investigation. Certainly, an earlier single case study by Mills (1986) identified a close association between food intolerance, depression and somatic symptoms and suggests that further work may be merited. Addolorato et al. (1996) confirmed this association and suggested that the intrinsic association between neurones and mast cells within the gastrointestinal tract could account for the direct influence of the central nervous system on gastric motility through smooth muscle regulation, thus making it conceivable for there to be an aetiopathogenesis between anxiety, IBS and food allergy. The similar nutrient intake between the group in the 
study by Jarrett et al. (1994) was interpreted as evidence that dietary factors play a limited role in the pathogenesis of FBD. As food intake was not weighed, however, only estimated from portion size, and with the lack of an IBS specific group, it is premature to draw such conclusions and the study must be viewed as a design pilot. The influence of ovarian hormones, which affect bowel habit (Vlitos \& Davies, 1996) was controlled for in this study by examining only data from the follicular phase of the menstrual cycle, in which intake is suppressed (Dalvit, 1981) and faeces are harder (Davies et al. 1986) owing to a combination of dietary and hormonal factors. Greater differences between controls and subjects may well occur during unsuppressed periods.

In summary, comparisons of the composition of diets between sufferers of IBS and healthy controls where a weighed dietary record was not taken must be viewed with extreme caution, as weights calculated from 'standard' portion sizes are likely to contain a significant degree of error. Even the weighed inventory is not without problems. The simple act of participating in such a study subtly influences the psychology of food and meal choice, either to simplify the recording process, or in an effort to 'please' the investigator.

All of the studies conducted using a weighed dietary inventory have failed to identify significant differences between the macronutrient intakes of women with and without FBD. Many investigators have taken this as a sign that diet is of limited significance as an aetiological factor, but it more likely confirms the hypersensitivity of the gut in IBS patients, where reactivity to quite 'normal' levels of intake results in symptom genesis. Such findings accord with the strategy of maintaining a balanced nutrient intake (Dotevall, 1985b), and it may also be of therapeutic benefit, in terms of reassurance, for the patient to be told that it is not their lack of dietary control that has caused their bowel problem, particularly given the high degree of neuroticism seen in IBS patients (Chakraborti et al. 1996).

\section{Physiological and psychological effects of eating disorder}

Eating disorders exist at the boundary of psychological and physical illness. Like IBS, they must be viewed in a biopsychosocial context. Young women suffering from eating disorders frequently report gastrointestinal symptoms such as abdominal pain and bloating (Gallo et al. 1996). In a study of 301 healthy female students, severity of dieting was positively related to the frequency of abdominal pain, bloating, diarrhoea and constipation (Krahn et al. 1996). Although the relationship between severity of dietary restriction and clinical IBS was not specifically investigated, early observations suggest that dieting is associated with the onset of gastrointestinal symptoms in young women. Dietary information was derived from eating attitude questionnaires, and prospective, weighed records were not made. To draw firmer conclusions with regard to the role of severe dieting and the onset of gastrointestinal symptoms and possibly IBS, a more rigorous study would be required, particularly in view of the fact that as the study population were derived from university campus medics, they may represent a specialized population subset, both in terms of age and social status. The finding that foodrelated IBS, like severe dieting, is more common in female than male subjects (Hunter, 1985) suggests that further observation may be worthwhile.

Crowell et al. (1994) reported a significant association between obesity, binge eating and symptoms of IBS. Obese subjects reported more frequent constipation, diarrhoea, straining at stool and flatus than normal weight controls. Assessment of eating attitudes in IBS patients using the Eating Attitudes Test produced inconclusive results (Sullivan et al. 1997). The statistical significance of differences in eating attitudes between IBS patients and those with eating 
disorders, inflammatory bowel disorder and healthy controls depended on the statistical method used. A significant difference was obtained between IBS, IBD, and controls $(P=0.05)$ when groups were compared using analysis of variance and the least significant difference test. The implications of this finding are manifest, suggesting a heightened role for eating disorder in the pathogenesis of IBS over other bowel disorders. Whether this is the cause of the bowel dysfunction, or results from it, remains unclear. Decreased energy intake has been observed in male and female IBS patients after onset (Debry \& Drouin, 1976) and is associated with life stress (Macht, 1996). A subgroup of IBS patients may actually have an eating disorder, either in isolation or comorbid with IBS. Given that the Eating Attitudes Test scores achieved by the eating disorders group were significantly higher on all subscales of the Eating Attitudes Test questionnaire than those for the IBS group, the latter appears more likely. This is perhaps not surprising, given the range of foods associated with symptoms (Table 5) and Hislop's assertion (1971) that postprandial pain is so severe in some patients that the desire to eat subsequent meals is reduced. Ragnarsson \& Bodemar (1998) found postprandial worsening of pain to occur in $49 \%$ of IBS patients, whereas only $10 \%$ reported pain relief by defaecation, leading them to suggest that postprandial worsening of pain should replace pain relief by defaecation as one of the cardinal diagnostic criteria for IBS.

Evidence for a mutually reinforcing role between gastrointestinal and psychiatric symptoms is also supplied by Hotopf et al. (1998), who found that children 7-15 years old with chronic abdominal pain were 2.7 times more likely to suffer from a psychiatric disorder in adulthood than those without such physical distress.

\section{Diet and stress}

Stress, perceived as a powerful symptom trigger by many sufferers with bowel dysfunction (Drossman et al. 1982), may also exert indirect effects upon the gastrointestinal tract, through modifications in diet-related behaviour in individuals under stress. Exam induced stress caused increased nicotine consumption, alcohol consumption, total energy intake, and decreased physical exercise in individuals with high levels of anxiety and low levels of social support (Pollard et al. 1995; Steptoe et al. 1996). Such deleterious fluctuations were not observed in a control group, and are therefore presumably attributable to the exam induced stress. Similar effects have been observed in older adults (Jennison, 1992; Weinstein et al. 1997). Johnsen et al. (1986) examined questionnaires from 14667 healthy adults, and identified low levels of physical activity to be associated with an increased number of symptoms of IBS in men, and increased cigarette consumption to be relevant in women. While direct inferences cannot be made, alimentary induced symptoms of IBS in these patients may occur as a result of behavioural reactions to stress that have known effects on the bowel (Oettle, 1991; Scott et al. 1992; Probert et al. 1995) and are consistently identified in trials of stress-related behaviour. Hill (1991) suggested that environmental factors profoundly affect nutrient absorption and are therefore an important factor in the aetiology of digestive diseases. Like the study by Johnsen $e t$ al. (1986), however, this effect was investigated in healthy individuals, and examination of such factors within IBS sufferers is required to confirm findings. Secondary causes of IBS are unlikely to account for a majority of cases, however, as it is men who most readily alter their health-related behaviour under stress (Mechanic, 1976; Horwitz \& Raskin-White, 1987).

A recent paper by Addolorato et al. (1997), however, on patients with inflammatory bowel disease, reported the inverse relationship, with anxiety and depression occurring as a result of malnutrition, itself presumably occurring as a result of bowel symptoms impairing adequate 
nutrition. Whether this is the case in IBS remains to be seen, but if so it could represent a closed cycle of gut symptoms, malnutrition, psychological impairment and reinforcing gut symptoms.

\section{Nutrients, stress and gastrointestinal physiology}

Postprandial rises in intestinal myoelectric and motor activity are well documented (Wangel \& Deller, 1965; Holdstock \& Misiewicz, 1970; Snape et al. 1978), and their magnitude dependent on the energy content of the meal (Snape et al. 1978; Thompson, 1989). Snape et al. (1978) found colonic motor and spike activity to be significantly increased $(P<0.02)$ in 16 healthy subjects after a $1000 \mathrm{kcal}$ test meal, but not after a $350 \mathrm{kcal}$ meal. An increase in serum gastrin was also observed after the larger meal, but the time course of gastrin increase was unrelated to that of the increase in motor activity, suggesting that gastrointestinal hormones are not the sole vectors responsible for postprandial alterations in colonic electric activity. The relevance of these findings to free-living subjects is somewhat questionable, as a $1000 \mathrm{kcal}$ meal is unlikely to be a daily occurrence for a majority of the population, especially considering recent trends towards consumption of 'healthier' low fat and low calorie products and the replacement of traditional meal patterns with 'grazing' habits (Hurson \& Corish, 1997; Engell et al. 1998; Lichtenstein et al. 1998). An interesting extension of this work would be to identify the crucial energy content at which significant motor activity is evoked. Such findings may have possible clinical implications.

Nutrient composition is also important. A mixed, test meal caused a significant increase in postprandial colonic spike activity, compared with the fasting state $(P<0.01)$. A $600 \mathrm{kcal}$ fat meal induced a similar increase in spike activity, plus an additional increase 70-90 minutes after eating $(P<0.02)$. Ingestion of neither $320 \mathrm{kcal}$ carbohydrate, nor $200 \mathrm{kcal}$ protein significantly altered the myoelectric response from that observed with the test meal (Wright $e t$ al. 1980). Ingestion of fat in isolation resulted in a different myoelectric pattern from the mixed meal, suggesting a symbiotic effect for protein and fat. A carbohydrate-fat combination induced a gastrocolonic response similar to the mixed meal, whereas the protein-fat combination abolished the late spike activity. In the healthy gastrointestinal system, therefore, nutrient components of the diet exert marked and varied effects on postprandial motility. Dietary fat is a potent stimulator of colonic myoelectric activity, whereas amino acids are inhibitors of the gastrocolonic response. Carbohydrate appears neutral and does not significantly affect the responses obtained when carbohydrate portions are added to fat, or fat and protein meal combinations. The inhibitory effect of amino acids was confirmed in 7 healthy subjects and 8 IBS sufferers (Battle et al. 1980), by recording of distal colonic motility using a bipolar clip-electrode perfused catheter apparatus, following a $1000 \mathrm{kcal}$ test meal with or without the prior addition of a protein hydrolysate solution composed of eight essential and eight nonessential amino acids. The meal plus protein combination resulted in suppression of the early colonic spike response in normal subjects $(P<0.01)$ and the characteristic late spike response in IBS patients $(P<0.01)$. The balance of the amino acid mixture, containing equal proportions of essential and nonessential acids, likely explains the discrepancy between these findings and contradictory earlier findings by Meshkinpour et al. (1974). Patients in the latter experiment ingested only essential amino acids, which are recognized as increasing motility through the release of cholecystokinin (CCK) (Battle et al. 1980). In reality, meals are likely to be composed of a mixture of amino acids, and thus Battle and coworkers' results are likely to be those encountered in vivo. 
Cann et al. (1983) measured whole gut transit time (WGTT) in symptom specific groups of IBS patients (selected for pain and distension, diarrhoea or constipation) and healthy controls. For the purposes of this experiment, WGTT was measured as the time taken to void half of the 50 radio-opaque marker pellets ingested with the test meal, which was determined by radiography of all stool samples passed $72 \mathrm{~h}$ after ingestion. WGTT was significantly shorter in patients with predominant diarrhoea $(P<0.01)$ and longer in those with constipation $(P=0.01)$ in comparison with normals. Thirty-four patients reported pain, particularly in the right iliac fossa, during a test meal, and in 25 onset of pain was associated with the arrival of food residues in the caecum, confirming IBS as a disease of the whole intestine. The significance of the results is only discussed with the IBS group considered heterogeneously, and the purpose of subdivision into symptom specific groups, apart from obtaining a broad sample of IBS patients, is rather nebulous, and in some instances at odds in the methodology. For constipation-predominant patients, a $72 \mathrm{~h}$ faecal observation period may simply not be sufficient.

Rectosigmoid pressure recordings were also conducted by Jepsen et al. (1989). Motility indices were calculated from pressure recordings taken in the lower sigmoid and upper rectum using continuously perfused catheters connected to pressure transducers, in 21 resting IBS subjects (three male, 18 female) after sham feeding, and ingestion of a standard meal. Each step of stimulation caused a significantly increased motility index $(P<0.01)$. The increase in rectosigmoid pressure activity after the sham feeding indicates the existence of a cephalic phase in the postprandial motor response of the colon in IBS, consistent with the biopsychosocial context in which the disease is now viewed (Bass, 1986; Drossman, 1996; Gwee, 1996). Jepsen and coworkers speak of IBS as being a disorder with possible 'neuropsychiatric implications'.

Katschinski et al. (1990) observed no significant differences in electric control activity (ECA) between IBS patients and healthy controls, either basally or postprandially. Incomparable subject populations, methods of bowel preparations, choice of recording site and device, and method of data analysis explain the disparity of the results with those of others. Gorard et al. (1994) identified faster orocaecal transit time in eight diarrhoea-predominant IBS patients than 12 normals $(P<0.05)$ despite comparable myoelectric activity. Indirect measurements of motility, such as ECA, measured in this experiment using a flexible catheter incorporating six strain-gauge transducers, may not therefore be relevant. The transducers were distributed along almost a metre of the gut, giving motility recordings over a much wider area than previously observed, which may account for the discrepancy between these results and those of others. Measurement of WGTT instead of orocaecal transit time may also have affected the results, given the role played by the colon in IBS. The frequency and organization of ECA in the rectosigmoid did not differ significantly between normal and IBS subjects in the resting state (Sarna et al. 1982). Ingestion of a meal did not significantly affect either frequency or organization of ECA in either group. Alterations in colonic ECA do not, therefore, appear to form the basis of the motility disturbances associated with symptoms of irritable bowel. Intraluminal pressure differences between IBS patients and controls did not reach statistical significance, and hypercontractility of the colon in IBS was not confirmed (Trotman \& Misiewicz, 1988). Methodological nuances may explain this finding in part. Pressure was measured only in the sigmoid, whereas the motility disturbance in the colon must be considered in its entirety, as pressure activity in the sigmoid is largely nonpropulsive (Rogers \& Misiewicz $1988 b)$.

The postprandial response to the ingestion of fat appears more marked in IBS (Phillips $e t$ al. 1992), where normal colonic responses to feeding are impaired (Sullivan et al. 1978). This response is also inhibited by anticholinergic drugs, suggesting mediation via cholinergic 
pathways (Sullivan et al. 1978; Thompson, 1989). Characteristically, the altered response is associated with pain after meals (Harvey \& Read, 1973; Wright et al. 1980; Cann et al. 1983). An increase in postprandial relative motility index was observed in patients with IBS compared with controls (Hamdorf et al. 1988; Phillips et al. 1992). Among IBS subgroups, patients with diarrhoea had a greater relative motility index than those with constipation. Rogers \& Misiewicz (1988a) measured an activity index based on intraluminal pressure recordings taken in the unprepared sigmoid colon using a three-lumen, water-perfused tube assembly systematically placed at distances $15-50 \mathrm{~cm}$ from the anus. The activity index was only significantly different between IBS subjects $(n=7)$ and controls $(n=7)$ postprandially $(P<0.05)$. The mean age of the IBS patients, however, was 51 years. As presentation of IBS is most common in the third and fourth decades of life (Fielding, 1977a), this makes the IBS population nonrepresentative, and further investigation warranted. Exaggerated preprandial motility has also been observed in some IBS patients (Vassallo et al. 1992).

Small et al. (1997) identified greater postprandial jejunal motility in IBS compared with normals $(P<0.001)$. Both diarrhoea- and constipation-predominant subjects exhibited greater frequencies of muscular contraction than subjects without IBS. The previously reported (Niderau et al. 1992) exaggerated colonic response to food in IBS was thus confirmed. While altered motility may be reflected by alterations in bowel habit, it is possible that altered sensory awareness of motor responses may be responsible for the abdominal pain with which they have been associated (Kellow \& Phillips, 1987; Phillips et al. 1992). Certainly, the perception threshold for physiological responses in the intestine has been shown to be lower in subjects with IBS than controls (Kellow et al. 1992).

The effects of stress on the motor function of the gut are also well documented, in both small intestine (McRae et al. 1982) and colon (Narducci et al. 1985; Welgan et al. 1988). McRae and coworkers, for example, identified inhibition of fasting motor complexes in the small intestine during a dichotomous listening test in 11 healthy medical students, using a pressure-sensitive radio-pill as previously described by Thompson et al. (1980). Gastric emptying is also modified (Thompson et al. 1983). In addition to life stress from external sources, the effects of stress must also be considered in relation to food, as once meals are perceived as a trigger of symptoms by the patient, mealtimes may themselves become stressful events, reinforcing the altered motor activity produced by food itself.

Considerable investigation has been undertaken regarding the effect of both nutrients and psychological stresses on gastrointestinal physiology. Study methods that are not comparable, particularly when complex measurements such as recording of ECA or gut motor responses are required, sometimes detract from the ability to draw conclusive statements. The most striking effects that have been observed to date are those relating to the effects of dietary fats and experimentally induced stresses on gut transit times. The data pertaining to rectosigmoid pressure, electric rhythms and the patterns of motor responsiveness are less conclusive, though indications that patients with IBS show exaggerations of normal responsiveness rather than distinct abnormalities can be viewed in a positive light with respect to the implications for treatment.

\section{The role of bile acids}

Ingestion of fat results in release of the digestive hormone CCK from the gallbladder (Chadwick et al. 1982), and is also associated with an increase in bile acid excretion (Gordon $e t$ al. 1956). Bile acids are diarrhoeogenic (Mekhjihan et al. 1971; Phillips, 1972) and stimulate 
colonic motility (Snape et al. 1979; Karaus \& Muller-Lissner, 1993). Excess faecal bile acid excretion has been identified in patients with IBS (Flynn et al. 1979). CCK stimulates ileal motor activity (Gutiérrez et al. 1974; Snape et al. 1978), and altered gallbladder responses to CCK have been identified in IBS patients (Kellow et al. 1987; Sjölund et al. 1996). Increased fat intake may therefore lead to an increase in bile acids, and symptoms of IBS. Diets with a high fat content affect the metabolic activity of colonic bacteria, and are associated with increased bile acid excretion, when compared with lower fat diets (Reddy \& Wynder, 1977). Low fat diets appear prudent in the management of IBS (Dotevall, 1985a) and have proved successful in bile acid induced diarrhoea (Eusufzai, 1995).

\section{Microbial infection}

Postinfective bowel dysfunction occurs in between $6 \%$ and $40 \%$ of gastroenteritis sufferers (Chaudhury \& Truelove, 1962; Hunter \& Alun-Jones, 1985; Neal et al. 1997a, b; Spiller, 1997). Many IBS sufferers first report symptoms subsequent to such infection (Chaudhury \& Truelove, 1960; McKendrick \& Read, 1994; Gwee et al. 1996). Foodborne pathogens therefore represent an indirect mechanism by which foodstuffs act as a causal factor in the development of IBS, secondary to initial infection. The persistence of symptoms following gastrointestinal infection is relatively short lived in the majority of cases, suggesting a degree of diagnostic confusion with more transient gut symptoms. Indeed, Sharma \& Chawla (1983) report common misdiagnosis of nondysenteric amoebic colitis with IBS in India.

Twenty nine percent of acute gastroenteritis patients studied by Gwee et al. (1996) were classified as having IBS. At the time of initial hospitalization, patients who subsequently went on to develop IBS showed a higher degree of psychological dysfunction than those who returned to normal bowel habit. Psychological factors may therefore predispose patients to the onset of IBS. Neurotic personality traits may result in subjects reacting to their initial illness in a more anxious and stressful way (Fossey \& Lydiard, 1990).

The possibility of microbial infection causing persistent gut damage was emphasized by Neal et al. $(1997 \mathrm{~b}$ ), in a large study of 544 people, one quarter of whom reported persistent alterations in their bowel habit six months after an episode of infective gastroenteritis. In $7 \%$ of subjects, gut dysfunction was consistent with a diagnosis of the irritable bowel syndrome, made using modified Rome criteria. The design of the study, using postal questionnaires, places some limit upon the quality of information derived, but allows access to a much larger sample population than would be possible using interview schedules. A smaller scale study along these lines would be helpful in confirming these preliminary findings.

\section{Pathological mechanisms}

Several possible mechanisms for postinfective IBS have been suggested (McKendrick \& Read, 1994). Increased permeability of the gut epithelium subsequent to gastrointestinal infection provides food antigens with access to the immunoreactive cells present in the submucosa. Previous injury of the intestinal epithelium by bile acids or parasitic infection may result in sensitivity to a specific antigen and hypersecretion, increased motor activity and the proliferation of mast cells upon repeat exposure. Niaz et al. (1997) reported chronic IBS-type symptoms after gastroenteritis, as a result of subsequent bile acid malabsorption. Neuropeptide 
involvement is another possible mechanism. The stimulation of afferent nerves by inflammatory mediators can result in neuropeptides forming in the cell bodies. These biogenic compounds are then transmitted along the length of the nerve fibres. In the spinal cord, it is possible that they encourage repeated transmission of sensory impulses, resulting in broad spectrum hyperalgesia in the area around the primary lesion. Bueno et al. (1997) suggested that local tissue injury and the subsequent release of inflammatory mediators trigger the release of 5hydroxytryptamine, which sensitizes nerve endings.

Simple disruption of the inherent colonic microflora population after gastrointestinal infection affects colonic function (King \& Hunter, 1996) and may be the relevant pathogenic mechanism in some patients. Such changes are thought to account for the onset of IBS that occurs after treatment with antibiotics in some patients (Alun-Jones et al. 1984; Lewis, 1995; Mendall \& Kumar, 1998). King et al. (1997) showed colonic fermentation to be greater in IBS than in healthy controls in response to a standard meal. When the study groups were fed exclusion diets, excretion of hydrogen and methane, measured using a whole body calorimeter, fell in both groups, but significantly more so in the IBS group $(P<0.05)$.

Post-gastroenteritis onset of IBS accounts for a significant minority of cases. In effect, these represent a specific subgroup, in whom the cause of functional disturbance is clearly attributable, a luxury not afforded to most sufferers. However, infective damage to the gut lining renders the sufferer vulnerable to the effects of food and stress in the same way as any other IBS patient, and therefore the historic knowledge of the onset of the condition may be of limited help in management terms.

A medium term follow up of all cases of severe gastroenteritis may be one pragmatic solution, so that intervention can be made at the earliest possible opportunity to minimize damage to the gut lining. However, such 'top-down' health promotion strategies are notoriously difficult to employ when administered from a central standpoint, and are unlikely to prove effective in the long term. More general awareness of the risks in the public arena may give greater success.

\section{Conclusions}

Dietary factors are widely recognized as powerful symptom triggers in IBS by both clinicians and patients (Dawson, 1994; Rees et al. 1994a), and are inherently associated with psychosocial stress, another powerful symptom trigger, which combines synergically with the former. The balance of the existence of these two key players may determine the development of IBS rather than other conditions with similar pathological basis (Veale et al. 1991).

The aetiological relationship between food per se and IBS is complex and often ill-defined. Methodological insufficiencies, particularly the number of trials in which the IBS population is poorly defined, both in terms of diagnosis and of demographics, and the lack of confirmation of results using double-blind food challenge, suggest that present knowledge should be viewed with a degree of caution and as early observations, with considerable further research warranted. In 1985, Truswell stated, with respect to the field of food sensitivity as a whole, that 'good clinical research has been lacking'; the situation has remained largely unchanged in the subsequent decade. A large study with an IBS population defined according to the Rome Criteria (Thompson et al. 1992), of sufficient duration to encompass the possibilities of delayed hypersensitivity and the characteristic waxing and waning of symptoms, and where symptom remission on exclusion and symptom regeneration on re-introduction of foods is confirmed using a double-blind challenge, has not been performed to date and is required before con- 
clusive statements can be made regarding the role of intolerance, allergy and aversion to food in the aetiopathogenesis of IBS. In view of the complex and multifarious aetiology, Vatn's advice (1997) to subdivide cases into immunologic, environmental and psychosomatic categories would appear logical. Intolerance to foods is undoubtedly responsible for some cases of IBS (Table 5), although the proportion ascribable to true, immunologically mediated allergy is relatively small. A proportion of superficially diet-related cases are undoubtedly of psychological origin. Lactose intolerance is an organic condition which has a symptom complex so reminiscent of IBS that misdiagnosis is likely.

The high degree of success that has been reported on long term exclusion diets (Table 4) suggests that the therapeutic potential for remission of symptoms by exclusion of foods is a distinct possibility for some patients, though the proportion of sufferers for whom this may be relevant cannot be gauged from studies to date owing to their methodological insufficiencies. Increasing our knowledge of the relationship between food and symptoms of IBS may eventually allow long term patient centred remission of symptoms, rather than the disease focused temporary pharmacological alleviation that is widely prescribed at present. The medical profession which, in view of the findings of this paper, has rightly been cautiously guarded when responding to the role of food as a symptom trigger, may now have to accept the possibility of considering dietary manipulation alongside pharmacological intervention as a means of treating the symptoms of IBS, the relevance of each treatment component being determined in an interactive manner fashioned from exploratory partnership between physician and patient. In fact, Colwell et al. (1998) reported that IBS patients undertaking health education classes which included nutrition information showed both short and long term pain relief $(P<0.01)$, confirming the therapeutic potential for dietary manipulation of IBS.

A causal role has also been postulated for dietary macronutrient content, both in terms of excess and insufficiency. Nutritional inadequacy of the diet has been promulgated as a potential cause in some patients, either directly or through secondary effects on the psyche. It is feasible that periodic changes in diet may contribute to the seasonal changes in symptoms reported by 23\% of sufferers (Talley et al. 1995a). Clinically diagnosable syndromes such as anorexia nervosa and bulimia nervosa are encountered (Fielding, 1977b) and have been aetiologically implicated; subclinical chronic dieting is frequently associated with the onset of abdominal symptoms.

Food may also act in a secondary manner, as the vehicle through which bacterial pathogens disrupt the integrity of the gastrointestinal system. Persistent IBS has been observed by many workers following gastrointestinal illness, particularly when combined with psychological stress. This is suggestive of a cumulative effect for predisposing factors, overcoming the body's biological defence mechanisms and ability to resist disease onset.

IBS is intrinsically associated with altered motor responsiveness of both the small (Kellow et al. 1987, 1988) and large (Sullivan et al. 1978; Latimer et al. 1981) bowel. The postprandial responses to food which naturally occur are thus exaggerated, and associated with symptoms of pain and diarrhoea. Experimentally induced stress has also been shown to affect these physiological phenomena (Latimer et al. 1981; Narducci et al. 1985). The sharing of common physiological pathways with alimentary factors emphasizes the synergic potential of the two triggers. Laboratory stress also affects perception of visceral sensation, providing a tangible association between psychological stress and abdominal pain, perhaps the cardinal symptom of the syndrome.

The potential for interaction between diet and stress is considerable, given the regularity with which the gastrointestinal system is forced to cope with the vicissitudes of each factor, and the common mechanistic pathways by which their effects on the gastrointestinal tract are 
achieved. A classic response to life stress involves behavioural or lifestyle change, including eating, alcohol consumption, smoking and exercise behaviour. Lifestyle factors have profound effects on the gastrointestinal tract and the psyche, and have been directly associated with symptoms of the syndrome in both males and females. The inverse relationship is also apparent, psychological status varying as a facet of dietary composition, and a self-perpetuating cycle may be initiated. Stress induced changes in motility and hypersensitivity may cause exaggerated responses to subsequent food ingestion, and conversely, foods that trigger gastrointestinal symptoms render the process of eating itself a stressor. At a clinical level, eating disorders appear to have aetiological significance. Other psychiatric conditions impinge upon dietary triggers via psychosomatic food aversion, and psychosocial factors moderate the way that incoming stressors are interpreted, and so are inextricably involved in formulation of the subjective stress response, which itself will have a psychological component. The interaction between dietary and psychological factors undoubtedly contributes to the aetiopathological alignment of IBS in occupying 'the fascinating hinterland between the mind and the gut' (Read, 1994), and is highly supportive of recent assertions that the long term care of IBS patients may be improved through collaboration between medical and psychological specialists (Kim \& Dundon, 1998).

The authors gratefully acknowledge financial assistance from Reckitt \& Colman Products Ltd.

\section{References}

Achord, J. (1979). Irritable bowel syndrome and dietary fiber. Joumal of the American Dietetic Association 75 , $452-453$.

Addolorato, G., Capristo, E., Stefanini, G. F. \& Gasbarrini, G. (1997). Inflammatory bowel disease: a study of the association between anxiety and depression, physical morbidity, and nutritional status. Scandinavian Journal of Gastroenterology 32, 1013-1021.

Addolorato, G., Gasbarrini, G., Marsigli, L. \& Stefanini, G. G. (1996). Irritable bowel syndrome and food allergy: an association via anxiety-depression? Gastroenterology 111, 833-834.

Alun-Jones, V., McLaughlan, P., Shorthouse, M., Workman, E. \& Hunter, J. O. (1982). Food intolerance, a major factor in the pathogenesis of Irritable Bowel Syndrome. Lancet ii, 1115-1117.

Alun-Jones, V., Shorthouse, M., Workman, E. \& Hunter, J. O. (1983). Food intolerance and the irritable bowel. Lancet ii, 633-634.

Alun-Jones, V., Wilson, A. J., Hunter, J. O. \& Robinson, R. E. (1984). The aetiological role of antibiotic prophylaxis with hysterectomy in irritable bowel syndrome. Journal of Obstetrics and Gynaecology 5, S22-S23.

Balsari, A., Ceccarelli, A., Dubini, F., Fesce, E. \& Poli, G. (1992). The faecal microbial population in the irritable bowel syndrome. Microbiologica 5, 185-194.

Barau, E. \& Dupont, C. (1990). Modifications of intestinal permeability during food provocation procedures in pediatric Irritable Bowel Syndrome. Joumal of Pediatric Gastroenterology and Nutrition 11, 72-77.

Barbara, L., Baldi, F. \& Longanesi, A. (1991). Pathogenesis of irritable bowel syndrome. Italian Journal of Gastroenterology 23, 35-38.

Bass, C. (1986). Life events and gastrointestinal symptoms. Gut 27, 123-126.

Battle, W. M., Cohen, S. \& Snape, W. J. (1980). Inhibition of postprandial colonic motility after ingestion of an amino acid mixture. Digestive Diseases and Sciences 25, 647-652.

Bauer, F. E., Bittner, R. \& Hampel, K.E. (1983). [Crohn's disease of the upper gastrointestinal tract]. Medizinische Welt 34, 67-69.

Bearcroft, C. P., Perrett, D. \& Farthing, M. J. G. (1998). Postprandial plasma 5-hydroxytryptamine in diarrhoea predominant irritable bowel syndrome: a pilot study. Gut 42, 42-46.

Bengtsson, U., Hanson, L. A. \& Ahlstedt, S. (1996). Survey of gastrointestinal reactions to foods in adults in relation to atopy, presence of mucus in the stools, swelling of joints and arthralgia in patients with gastrointestinal reactions to foods. Clinical and Experimental Allergy 26, 1387-1394.

Bennett, E. J., Piesse, C., Palmer, K., Badcock, C.-A., Tennant, C. C. \& Kellow, J. E. (1998). Functional gastrointestinal disorders: psychological, social and somatic features. Gut 42, 414-420. 
Bentiey, S. J., Pearson, D. J. \& Rix, K. J. B. (1983). Food hypersensitivity in Irritable Bowel Syndrome. Lancet ii, 295-297.

Besterman, H. S., Sarson, D. L., Rambaud, J. C., Stewart, J. S., Guerin, S. \& Bloom, S. R. (1981), Gut hormone responses in the Irritable Bowel Syndrome. Digestion 21, 219-224.

Bindslev-Jensen, C. (1998). Food allergy. British Medical Journal 316, 1299-1302.

Birtwhistle, S. (1983). Food intolerance and the irritable bowel (reply). Lancet ii, 633.

Bockus, H. L., Bank, J. \& Wilkinson, S. A. (1928). Neurogenic mucous colitis. American Journal of Medical Science 176, 813-829.

Bolin, T. D., Davis, A. E. \& Duncombe, V. M. (1982). A prospective study of persistent diarthoea. Australia and New Zealand Journal of Medicine 12, 22-26.

Bradley, H. K., Wyatt, G. M., Bayliss, C. E. \& Hunter, J. O. (1987). Instability in the faecal flora of a patient suffering from food-related Irritable Bowel Syndrome. Journal of Medical Microbiology 23, 29-32.

Bueno, L., Fioramonti, J., Delvaux, M. \& Frexinos, J. (1997). Mediators and pharmacological sensitivity: from basic to clinical investigations. Gastroenterology 112, 1714-1743.

Burgio, G. R., Flatz, G., Barbera, C., Patané, R., Boner, A., Cajozzo, C. \& Flatz, S. D. (1984). Prevalence of primary adult lactose malabsorption and awareness of milk intolerance in Italy. American Journal of Clinical Nutrition 39, $100-104$.

Camilleri, M. \& Choi, M. G. (1997). Review article. Irritable Bowel Syndrome. Alimentary Pharmacology and Therapeutics 11, 3-15.

Canada Department of National Health and Welfare (1973). In Nutrition Canada National Survey. Nutrition: A National Priority. Ottawa: Canada Department of National Health and Welfare.

Cann, P. A., Read, N. W., Cammack, J., Childs, H., Holden, S., Kashman, R., Longmore, J., Nix, S., Simms, N., Swallow, K. \& Weller, J. (1983). Psychological stress and the passage of a standard meal through the stomach and small intestine in man. Gut 24, 236-240.

Cann, P. A., Read, N. W. \& Holdsworth, C. D. (1984). What is the benefit of coarse wheat bran in Irritable Bowel Syndrome? Gut 25, 168-173.

Carini, C., Brostoff, J. \& Wraith, D. G. (1987). IgE complexes in food allergy. Annals of Allergy 59, 110-117.

Chadwick, V.S., Maton, P.N. \& Selden, A.C. (1982). Gallbiadder contraction: hormonal regulation. In Bile Acids in Gastroenterology, p.153. Lancaster: MTP Press.

Chakraborti, S. K., Dey, B. K., Ghosh, N., Chaudhury, A. N. \& Mazumder, D. N. G. (1996). Objective evaluation of psychological abnormality in irritable bowel syndrome. Indian Joumal of Gastroenteralogy 15, 43-45.

Chalmers, F. W., Clayton M. M., Gates, L. O., Tucker, R. E., Wertz, A. W., Young, C. M. \& Foster, W. D. (1952). The dietary record-how many and which days? Journal of the American Dietetic Association 28, 711-717.

Chang, L. (1996). Evolving therapies for functional colonic disorders. Current Opinion in Gastroenterology 12, 32-38.

Chaudhury, N. A. \& Truelove, S. C. (1960). Human colonic motility: a comparative study of normal subjects, patients with ulcerative colitis and patients with the irritable colon syndrome. III. Effects of emotions. Gastroenterology 40, 7-36.

Chaudhury, N. A. \& Truelove, S. C. (1962). The Irritable Colon Syndrome: a study of the clinical features, predisposing causes and prognosis in 130 cases. Quarterly Journal of Medicine 31, 307-322.

Christensen, L. \& Somers, S. (1995). Comparison of nutrient intake among depressed and nondepressed individuals. Intermational Journal of Eating Disorders 20, 105-109.

Colwell, L. J., Prather C. M., Phillips, S. F. \& Zinsmeister A. R. (1998). Effects of an irritable bowel syndrome educational class on health-promoting behaviors and symptoms. American Journal of Gastroenterology 93, 901-905.

Coremans, G., Dapoigny, M., Muller-Lissner, S., Pace, F., Smout, A., Stockbrugger, R. W. \& Whorwell, P. J. (1995). Diagnostic procedures in the irritable bowel syndrome. Digestion 56, 76-84.

Coxe, M. (1998). Irritable bowel syndrome. Lancet 351, 673-674.

Creed, F. (1994). Irritable bowel or irritable mind? Psychological treatment is essential for some. British Medical Journal 309, 1647-1648.

Crowell, M. D., Cheskin, L. J. \& Musial, F. (1994). Prevalence of gastrointestinal symptoms in obese and normal weight binge eaters. American Journal of Gastroenterology 89, 387-391.

DaCosta, J. M. (1871). Membranous enteritis. American Journal of Medical Sociology 62, 321.

Dalvit, S. P. (1981). The effect of the menstrual cycle on patterns of food intake. American Journal of Clinical Nutrition 34, $1811-1815$.

Davies, G. J., Crowder, M., Reid, B. \& Dickerson, J. W. T. (1986). Bowel function measurements of individuals with different eating patterns. Gut 27, 164-169.

Dawson, A. M. (1994). The Irritable Bowel. Practitioner 228, 797-800.

Debry, G. \& Drouin, P. (1976). Diet in functional disorders of the colon. Progress in Food and Nutrition Science 2, 1-10.

Dotevall, G. (1985a). In Stress and Common Gastrointestinal Disorders: a comprehensive approach, p.97 [G. Dotevall, editor]. New York: Praeger.

Dotevall, G. (1985b). In Stress and Common Gastrointestinal Disorders: a comprehensive approach, p.123 [G. Dotevall, editor]. New York: Praeger.

Drossman, D. A. (1996). Gastrointestinal illness and the biopsychosocial model. Journal of Clinical Gastroenterology 22, 252-254. 
Drossman, D. A., Powell, D. W. \& Sessions, J. T. (1977). Clinical Gastroenterology conference. The Irritable Bowel Syndrome. Gastroenterology 73, 811-812.

Drossman, D.A., Sandler, R.S., McKee, D.C. \& Lovity, A.J. (1982). Bowel patterns among subjects not seeking health care. Use of a questionnaire to identify a population with bowel dysfunction. Gastroenterology 83, $529-534$.

Drossman, D. A., Thompson, W. G., Talley, N. J., Funch-Jensen, P., Janssens, J. \& Whitehead, W. E. (1990). Identification of sub-groups of functional gastrointestinal disorders. Gastroenterology International 3, $159-172$.

Drossman, D.A., Whitehead, W.E. \& Camilleri, M. (1997). Irritable Bowel Syndrome: a technical review for practice guidelines. Gastroenterology 112, 2120-2137.

Egger, J. (1997). Food, brain and behaviour: hyperkinetic syndrome. Journal of Nutritional and Environmental Medicine 7, 353-357.

Egger, J., Carter, C. M., Wilson, J., Turner, M. W. \& Soothill, J. F. (1983). Is migraine food allergy? A double-blind controlled trial of oligoantigenic diet treatment. Lancet it, 865-868.

Enck, P., Holtkötter, B., Whitehead, W. E., Schuster, M. M. \& Wienbeck, M. (1989) [Clinical symptoms, psychopathology and intestinal motility in patients with 'irritable bowel'.] Zeitschrift für Gastroenterologie 27, 357-361.

Enck, P., Kremer, A., Kuhlbusch, R., Niderau, C., Erckenbrecht, J. F. \& Berges, W. (1990). Prevalence of lactose malabsorption among patients with functional bowel disorders. Zeitschrift für Gastroenterologie 28, 239-241.

Enck, P., Steckler, I., Whitehead, W. E., Tucker, H. \& Schuster, M. M. (1984). Lactose intolerance versus Irritable Bowel Syndrome: physiological and psychological comparison. Gastroenterology 86, 1070.

Engell, D., Bordi, P., Borja, M., Lamber, C. \& Rolls, B. (1998). Effects of information about fat content on food preferences in pre-adolescent children. Appetite 30, 269-282.

Eusufzai, S. (1995). Bile acid malabsorption: mechanisms and transport. Digestive Diseases 13, 312-321.

Everhart, J. E. \& Renault, P. F. (1991). Irritable bowel syndrome in office-based practice in the United States. Gastroenterology 100, 998-1005.

Farah, D. A., Calder, I., Benson, L. \& MacKenzie, J. F. (1985). Specific food intolerance: its place as a cause of gastrointestinal symptoms. Gut 26, 164-168.

Farthing, M. J. G. (1995). Treatment of the Irritable Bowel Syndrome: food intolerance may play a part (reply). British Medical Journal 310, 1067.

Ferguson, A., Sircus, W. \& Eastwood, M. A. (1977). Frequency of functional gastrointestinal disorders. Lancet i, $1062-1064$.

Fielding, J. F. (1977a). A year in out-patients with the irritable bowel syndrome. Irish Joumal of Medical Science 146, $162-166$.

Fielding, J. F. (1977b). The Irritable Bowel Syndrome. Clinics in Gastroenterology 6, 607-622.

Floch, M. H. (1988). The Irritable Bowel Syndrome: the possible link between dietary fiber deficiency and disturbed intestinal motility. American Joumal of Gastroenterology 83, 963-964.

Flynn, M., Darby, C., Hammond, P. \& Taylor, I. (1979). Relationship between faecal bile acid excretion and myoelectrical activity in the irritable colon syndrome. Gut 20, A946.

Fossey, M. D. \& Lydiard, R. B. (1990). Anxiety and the gastrointestinal system. Psychiatric Medicine 8, $175-186$.

Fowlie, S., Eastwood, M. A. \& Ford, M. J. (1992). Irritable Bowel Syndrome: the influence of psychological factors on the symptom complex. Journal of Psychosomatic Research 36, 169-173.

Francis, C. Y. \& Whorwell, P. J. (1994). Bran and the irritable bowel syndrome-time for reappraisal? Lancet 344, $39-40$.

Friedman, G. (1991). Diet and the Imitable Bowel Syndrome. Gastroenterology Clinics of North America 20, 313-324.

Fry, J. (1985). Functional disorders. In Common Diseases: their nature, incidence and care, p.207 [J. Fry, editor]. Lancaster: MTP Press.

Gallo, C., Vighi, G., Pelligrini, M. P. \& Ortolani, C. (1996). Irritable bowel: a food allergy? Monographs in Allergy 32 , 198-203.

Gee, M. I., Grace, M. G. A., Wensel, R. H., Sherbaniuk, R. W. \& Thomson, A. B. R. (1985). Nutritional status of gastroenterology outpatients: comparison of inflammatory bowel disease with functional disorders. Joumal of the American Dietetic Association 12, $1591-1599$.

Gerrard, J. W. (1984). Food intolerance. Lancet ii, 413.

Gertner, D. \& Powell-Tuck, J. (1994). Irritable Bowel Syndrome and food intolerance. Practitioner 238, $499-504$.

Gorard, D. A., Libby, G. W. \& Farthing, M. J. G. (1994). Ambulatory small intestinal motility in diarrhoea predominant Irritable Bowel Syndrome. Gut 35, 203-207.

Gordon, H., Lewis, B., Eales, L. \& Brock, J. F. (1956). Effect of different dietary fats on the faecal end products of cholesterol metabolism. Nature 180, 993-994.

Grimes, D. S. (1976). Refined carbohydrate, smooth-muscle spasm and diseases of the colon. Lancet i, $395-397$.

Gudmand-Hoyer, E. (1994). The clinical significance of disaccharide maldigestion. American Journal of Clinical Nutrition 59, 735S-741S.

Gutiérrez, J. G., Chey, W. Y. \& Dinoso, V. P. (1974). Actions of cholecystokinin and secretin on the motor activity of the small intestine in man. Gastroenterology 67, 35-41.

Gwee, K.A. (1996). Irritable Bowel Syndrome: psychology, biology and warfare between false dichotomies. Lancet $347,1267$. 
Gwee, K. A., Graham, J. C., McKendrick, M. W., Collins, S. M., Marshall, J. S., Waiters, S. J. \& Read, N. W. (1996). Psychometric scores and persistence of Irritable Bowel after infectious diarrhoea. Lancet 347, 150-155.

Hahn, B. A., Saunders, W. B. \& Maier, W. C. (1997). Differences between individuals with self-reported irritable bowel syndrome (IBS) and IBS-like symptoms. Digestive Diseases and Sciences 42, 2585-2590.

Hamdorf, J. M., Ingram, D. M., Sallie, R. J. \& Hoffman, N. E. (1988). The motility of the colon in irritable bowel syndrome. Hepatogastroenterology 35, 208.

Harvey, R. F. \& Read, A. E. (1973). Effect of cholecystokinin on colonic motility and symptoms in patients with the Irritable Bowel Syndrome. Lancet i, 1-3.

Hawthorne, B., Lambert, S., Scott, D. \& Scott, B. (1991). Food intolerance and the Irritable Bowel Syndrome. Journal of Human Nutrition and Dietetics 3, 19-23.

Hill, P. (1991). It is not what you eat but how you eat it: digestion, lifestyle, nutrition. Nutrition 7, 385-395.

Hillman, L. C., Stace, N. H., Fisher, A. \& Pomare, E. W. (1982). Dietary intakes and stool characteristics of patients with the Irritable Bowel Syndrome. American Joumal of Clinical Nutrition 36, 626-629.

Hislop, I. G. (1971). Psychological significance of the irritable colon syndrome. Gut 12, 452-457.

Hochstrasser, B. \& Angst, J. (1996). The Zurich study. XXII. Epidemiology of gastrointestinal complaints and comorbidity with anxiety and depression. European Archives of Psychiatry and Clinical Neuroscience 246, 261-272

Holdstock, D. J. \& Misiewicz, J. J. (1970). Factors controlling colonic motility: colonic pressures and transit after meals in patients with gastrectomy, pernicious anaemia or duodenal ulcer. $G u t 11,100-110$.

Horwitz, A. \& Raskin-White, H. (1987). Gender-role orientations and styles of pathology among adolescents. Joumal of Health and Social Behavior 28, 158-170.

Hotopf, M., Carr, S., Mayou, R., Wadsworth, M. \& Wessley, S. (1998). Why do children have chronic abdominal pain, and what happens to them when they grow up? Population based cohort study. British Medical Joumal 316, 1196-1200.

Houghton, L. A., Heyman, D. J. \& Whorwell, P. J. (1996). Symptomatology, quality of life and economic features of irritable bowel syndrome - the effect of hypnotherapy. Alimentary Pharmacology and Therapeutics 11, 553-559.

Hunter, J. O. (1985). Irritable Bowel Syndrome. Proceedings of the Nutrition Society 44, 141-143.

Hunter, J O. (1991). Hypothesis: Food allergy-or enterometabolic disorder? Lancet 338, 495-496.

Hunter, J. O. (1998). The dietary management of the irritable bowel syndrome. Carbohydrates 8, 1-3.

Hunter, J. O. \& Alun-Jones, V. (1985). Studies on the pathogenesis of Irritable Bowel Syndrome produced by food intolerance. In pp. 185-190 [N.W. Read, editor]. New York: Grune and Stratton

Hunter, J. O., Workman, E. \& Alun-Jones, V. (1985). The role of diet in the management of Irritable Bowel Syndrome. In Topics in Gastroenterology, pp. 305-313 [P.R. Gibson \& D.P. Jewell, editors]. Oxford: Blackwell Scientific.

Hurson, M. \& Corish, C. (1997). Evaluation of lifestyle, food consumption and nutrient intake patterns among Irish teenagers. Irish Journal of Medical Science 166, 225-230.

Jarrett, M., Heitkemper, M. M., Bond, E. F. \& Georges, J. (1994). Comparison of diet composition in women with and without functional bowel disorder. Gastroenterology Nursing 6, 253-258.

Jennison, K. M. (1992). The impact of stressful life events and social support on drinking among older adults: a general population survey. International Joumal of Aging and Human Development 35, 9-123.

Jepsen, J. M., Skoubo-Kristensen, E. \& Elsborg, L. (1989). Rectosigmoid motility response to sham feeding in Irritable Bowel Syndrome. Evidence of a cephalic phase. Scandinavian Journal of Gastroenterology 24, 53-56.

Johnsen, R., Jacobsen, B. K. \& Forde, O. H. (1986). Associations between symptoms of irritable colon and psychological and social conditions and lifestyle. British Medical Journal 292, 1633-1635.

Jones, R. H. (1996). Clinical economics review: gastrointestinal disease in primary care. Alimentary Phamacology and Therapeutics 10, 233-239.

Karaus, M. \& Muller-Lissner, S. A. (1993). Motility and lower gut symptoms. European Joumal of Gastroenterology and Hepatology 5, 990-998.

Katschinski, M., Lederer, P., Ellermann, A., Ganzleben, R., Lux, G. \& Amold, R. (1990). Myoelectric and manometric patterns of human rectosigmoid colon in Irritable Bowel Syndrome and diverticulosis. Scandinavion Joumal of Gastroenterology 25, 761-768.

Kellow, J. E., Eckersley, G. M. \& Jones, M. (1992). Enteric and central contributions to intestinal dysmotility in irritable bowel syndrome. Digestive Diseases and Sciences 37, 168-174.

Kellow, J. E., Miller, L. J., Phillips, S. F., Zinsmeister, A. R. \& Charboneau. J. W. (1987). Altered sensitivity of the gallbladder to cholecystokinin-octapeptide in irritable bowel syndrome. American Joumal of Physiology 253, G650-655.

Kellow, J. E. \& Phillips, S. F. (1987). Small bowel motility in Irritable Bowel Syndrome is correlated with symptoms. Gastroenterology 92, 1885-1892.

Kellow, J. E., Phillips, S. F., Miller, L. J. \& Zinsmeister, A. R. (1988). Dysmotility of the small intestine in Irritable Bowel Syndrome. Gut 29, 1236-1243.

Kim, E.C. \& Dundon, M. (1998). Medical and psychological aspects of irritable bowel syndrome. Lippincott's Primary Care Practice 2, 329-340.

King, T. S., Elia, M. \& Hunter, J. O. (1997). Rapid colonic fermentation associated with symptoms in irritable bowel syndrome (IBS) is corrected by exclusion diet. Gastroenterology 112, A761.

King, T.S. \& Hunter, J.O. (1996). Anxiety and the Irritable Bowel Syndrome. Lancet 347, 617.

King, T. S. \& Hunter, J. O. (1997). Quality of life in irritable bowel syndrome (IBS): does it improve with resolution of symptoms? Gastroenterology 112, A761 
Kirkmayer, L. J. \& Robbins, J. M. (1996). 'Patients who somatize in primary care: a longitudinal study of cognitive and social characteristics.' Psychological Medicine 26, 937-951.

Krahn, D., Kurth, C., Naim, K., Redmond, L., Drewnowski, A. \& Gomberg, E. (1996). Dieting severity and gastrointestinal symptoms in college women. Joumal of American College Health 45, 67-71.

Kumar, D., Pfeffer, J. \& Wingate, D. L. (1990). Role of psychosocial factors in the irritable bowel syndrome. Digestion 45, 80-87.

Latimer, P., Sarna, S., Campbell, D., Latimer, M., Waterfall, W. \& Daniel, E. E. (1981). Colonic motor and myoelectrical activity: a comparative study of normal subjects, psychoneurotic patients and patients with Irritable Bowel Syndrome. Gastroenterology 80, 893-901.

Lessof, M. H., Wraith, D. G., Merrett, T. G., Merrett, J. \& Buisseret, P. D. (1980). Food allergy and intolerance in 100 patients - local and systemic effects. Quarterly Joumal of Medicine 195, 259-271.

Lewis, P. J. (1995). Treatment of the irritable bowel syndrome: food intolerance may play a part. Lancet $310,1067$.

Lichtenstein, A. H., Kennedy, E., Barrier, P., Danford, D., Ernst, N. D., Grundy, S. M., Leveille, G. A., Van Horn, L., Williams, C. L. \& Booth, S. L. (1998). Dietary fat consumption and health. Nutrition Reviews 56, S3-S19.

Lisker, R., Solomons, N. W., Perez Briceno, R. \& Ramirez Mata, M. (1989). Lactase and placebo in the management of the irritable bowel syndrome: a double-blind, cross-over study. American Joumal of Gastroenterology 84, $756-762$.

Longstreth, G. F. \& Wolde-Tsadik, G. (1993). Irritable bowel-type symptoms in HMO examinees: prevalence, demographics, and clinical correlates. Digestive Diseases and Sciences 38, 1581-1589.

Lovibond, P. F. \& Lovibond, S. H. (1995). The structure of negative emotional states: comparison of the depression anxiety stress scales (DASS) with the Beck depression and anxiety inventories. Behavior Research and Therapy 33, 335-343.

Lucey, M. R., Clark, M. L., Lowndes, J. O. \& Dawson, A. M. (1987). Is bran efficacious in Irritable Bowel Syndrome? A double-blind placebo controlled crossover study. Gut 28, 221-225.

McEvoy, R. (1989). Bowel-flora alteration: a potential cure for inflammatory bowel disease and Irritable Bowel Syndrome? Medical Joumal of Australia 151, 612.

Macht, M. (1996). Effects of high- and low-energy meals on hunger, physiological processes and reactions to emotional stress. Appetite 26, 71-88.

McKee, A. M., Prior, A. \& Whorwell, P. J. (1987). Exclusion diets in Irritable Bowel Syndrome: are they worthwhile? Joumal of Clinical Gastroenterology 9. 526-528.

McKendrick, M. W. \& Read, N. W. (1994). Irritable Bowel Syndrome-post salmonella infection. Journal of Infection 29, 1-3.

McRae, S., Younger, K., Thompson, D. G. \& Wingate, D. L. (1982). Sustained mental stress alters human jejunal motor activity. Gut 23, 404-409.

Manning, A. P., Thompson, W. G., Heaton, K. W. \& Morris, A. F. (1978). Towards positive diagnosis of the Irritable Bowel Syndrome. British Medical Joumal ii, 653-654.

Maxton, D. G., Morris, J. A. \& Whorwell, P. J. (1989). Ranking of symptoms by patients with the irritable bowel syndrome. British Medical Journal 299, 1138.

Mechanic, D. (1976). Sex, illness behavior and the use of health services. Journal of Human Stress 2, 29-40.

Mekhjian, H. S., Phillips, S. F. \& Hoffman, A.F. (1971). Colonic secretion of water and electrolytes induced by bile acids: perfusion studies in man. Joumal of Clinical Investigation 50, 1569-1577.

Mendall, M. A. \& Kumar, D. (1998). Antibiotic use, childhood affluence and irritable bowel syndrome. European Journal of Gastroenterology and Hepatology 10, 59-62.

Meshkinpour, H., Dinoso, V.P. \& Lober, S. H. (1974). Effect of intra-duodenal administration of essential amino acids and sodium oleate on motor activity of the sigmoid colon. Gastroenterology 66, 373-377.

Middleton, S. J., Coley, A. \& Hunter, J. O. (1992). The role of faecal Candida albicans in the pathogenesis of foodintolerant irritable bowel. Postgraduate Medical Journal 68, 453-454.

Mills, N. (1986). Depression and food intolerance: a single case study. Human Nutrition: Applied Nutrition 40, $141-145$

Millstone, E. (1997). Adverse reactions to food additives: the extent and severity of the problem. Journal of Nutritional and Environmental Medicine 7, 323-332.

Misra, S. P., Thorat, V. K., Sachdev, G. K. \& Anand, B. S. (1989). Long-term treatment of irritable bowel syndrome: results of a randomised control trial. Quarterly Journal of Medicine 73, 931-939.

Mitchell, C. M. \& Drossman, D. A. (1987). Survey of the AGA membership relating to patients with functional gastrointestinal disorder. Gastroenterology 92, 1282-1284.

Morris-Yates, M., Talley, N. J., Boyce, P. M., Nandurkar, S. \& Andrews, G. (1998). Evidence of a genetic contribution to functional bowel disorder. American Joumal of Gastroenterology 93, 1311-1317.

Mortensen, P. B. \& Clausen, M. R. (1996). Short-chain fatty acids in the human colon: relation to gastrointestinal health and disease. Scandinavian Joumal of Gastroenterology 216, 132-148.

Nanda, R., James, R., Smith, H., Dupley, C.R.K. \& Jewell, D.P. (1989). Food intolesance and the Irritable Bowel Syndrome. Gut 30, 1099-1104.

Narducci, F., Snape, W. J., Battle, W. M., London, R. L. \& Cohen, S. (1985). Increased colonic motility during exposure to a stressful situation. Digestive Diseases and Sciences 30, 40-44. 
Neal, K. R., Hebden, J. \& Spiller, R. (1997a). Prevalence of gastrointestinal symptoms six months after bacterial gastroenteritis and risk factors for development of the Irritable Bowel Syndrome: postal survey of patients. British Medical Journal 314, 779-782.

Neal, K. R., Hebden, J. \& Spiller, R. (1997b). Prevalence of gastrointestinal symptoms after bacterial gastroenteritis. Author's reply. British Medical Journal 314, 1903.

Newcomer, A. D. \& McGill, D. B. (1983). Irritable Bowel Syndrome. Role of lactase deficiency. Mayo Clinic Proceedings 58, 339-341.

Niaz, S.K., Sandrasegaran, K., Renny, F.H. \& Jones, B.J. (1997). Post-infective diarrhoea and bile acid malabsorption. Joumal of the Royal College of Physicians 31, 53-56.

Niderau, C., Faber, S. \& Karus, M. (1992). Cholecystokinin's role in regulation of motility in health and Irritable Bowel Syndrome. Gastroenterology 102, 1889-1898.

Ninan, T. K. \& Russell, G. (1992). Respiratory symptoms and atopy in Aberdeen school children: two surveys 25 years apart. British Medical Journal 304, 873-875.

Oettle, G. J. (1991). Effect of moderate exercise on bowel habit. Gut 32, 941-944.

Painter, N. S. (1972). Irritable or irritated bowel? Lancet ii, 46.

Parker, T. J., Naylor, S. J., Riordan, A. M. \& Hunter, J. O. (1995). Management of patients with food intolerance in irritable bowel syndrome: the development and use of an exclusion diet. Journal of Human Nutrition and Dietetics 8 , 159-166.

Patrick, D. L., Drossman, D. A., Frederick, I. O., DiCesare, J. \& Puder, K. L. (1998). Quality of life in persons with irritable bowel syndrome: development and validation of a new measure. Digestive Diseases and Sciences 43 , $400-411$

Paulley, J.W. (1984). The psychological management of the irritable colon. Hepatogastroenterology 30, 53-54.

Pearson, D. J. (1986). Pseudo food allergy. British Medical Journal 292, 221-222.

Pearson, D. J., Rix, K. B. \& Bentley, S. J. (1983). Food allergy: how much is in the mind? A clinical and psychiatric study of suspected food allergy. Lancet i, 1259-1261.

Petersdorf, R. F., Adams, R. D., Braunwald, E. et al. (1983). In Harrison's Principles of Internal Medicine IR.F. Petersdorf et al., editors]. New York: McGraw-Hill.

Petitpierre, M., Gumowski, P. \& Girard, J. P. (1985). Irritable Bowel Syndrome and food allergy. Annals of Allergy 54. 538-540.

Phillips, S. F. (1972). Diarrhea: a current view of the pathophysiology. Gastroenterology 63, 495-518.

Phillips, S. F., Talley, N. J. \& Camilleri, M. (1992). The Irritable Bowel Syndrome. In Motility Disorders of the Gastrointestinal Tract, pp. 299-326 [S. Anuras, editor]. New York: Raven Press.

Pollard, T.M., Steptoe, A., Canaan, L., Davies, G.J. \& Wardle, J. (1995). Effects of academic stress on eating behaviour and blood lipid levels. International Journal of Behavioural Medicine 2, 299-320.

Probert, C. S. J., Emmett, P. M. \& Heaton, K. W. (1995). Some determinants of whole-gut transit time: a populationbased study. QJM: Monthly Joumal of the Association of Physicians 88, 311-315.

Ragnarsson, G. \& Bodemar, G. (1998). Pain is temporally related to eating but not to defaecation in the irritable bowel syndrome: patients descriptions of diarrhoea and constipation and symptom variation during a prospective 6-week study. European Journal of Gastroenterology and Hepatology 10, 415-421.

Read, N.W. (1990). Functional gastrointestinal disorders: building castles in the air. Gastroenterology Intemational 3, 182-183.

Read, N. W. (1994). Irritable Bowel Syndrome: overview. European Journal of Gastroenterology and Hepatology 6. $457-459$.

Reddy, B. S. \& Wynder, E. L. (1977). Metabolic epidemiology of colon cancer: faecal bile acids and neutral steroids in colon cancer patients and patients with adenomatous polyps. Cancer 39, 2533-2539.

Rees, G. A., Davies, G. J., Parker, M. \& Trevan, M. (1994a). Gastrointestinal symptoms and diet of members of an Irritable Bowel Syndrome self-help group. Journal of the Royal Society of Health 114, 182-187.

Rees, G. A., Trevan, M. \& Davies, G. J. (1994b). Dietary fibre modification and the symptoms of Irritable Bowel Syndrome-a review. Journal of Human Nutrition and Dietetics 7, 178-189.

Rippere, V. (1983). Food allergy: how much is in the mind? Lancet ii, 45.

Rix, K. J. B., Pearson, D. J. \& Bentley, S. J. (1984). A psychiatric study of patients with supposed food allergy. British Journal of Psychiatry 145, 121-126.

Rogers, J. \& Misiewicz, J. J. (1988a). Increased intraluminal pressures and activity in the sigmoid colon of patients with the Irritable Bowel Syndrome. Hepatogastroenterology 35, 209-210.

Rogers, J. \& Misiewicz, J. J. (1988b). Relationship between transit and motility of the sigmoid colon in normals. Hepatogastroenterology 35, 209.

Royal College of Physicians (1984). Food intolerance and food aversion. Journal of the Royal College of Physician 18, 83-123.

Ryan, W. A., Fielding, J. F. \& Kelly, M. G. (1983). Personality and the irritable bowel syndrome. Irish Medical Journal 76, 140-141.

Sandler, R. S., Drossman, D. A., Nathan, H. P. \& McKee, D. H. (1984). Symptom complaints and health care seeking behaviour in subjects with bowel dysfunction. Gastroenterology 87, 314-318. 
Sama, S., Latimer, P., Campbell, D. \& Waterfall, W. E. (1982). Effect of stress, meal and neostigmine on rectosigmoid electrical control activity (ECA) in normals and in Irritable Bowel Syndrome patients. Digestive Diseases and Sciences 27, 582-591.

Schmidt, M. \& Floch M. H. (1992). Food hypersensitivity and the irritable bowel syndrome. American Joumal of Gastroenterology 87, 18-19.

Scott, A. M., Kellow, J. E., Eckersley, G. M., Nolan, J. M. \& Jones, M. P. (1992). Cigarette smoking and nicotine delay postprandial mouth-cecum transit time. Digestive Diseases and Sciences 37, 1544-1547.

Segal, I. \& Hunt, J. A. (1975). The Irritable Bowel Syndrome in the urban South African negro. South African Medical Joumal 49, 1645-1646.

Segal, I. \& Walker, A. R. P. (1984). The Irritable Bowel Syndrome in the black community. South African Medical Joumal 64, 885-886.

Sharma, M. P. \& Chawla, Y. (1983). Irritable Bowel Syndrome. Joumal of the Association of Physicians of India 31, $163-166$.

Sjölund, K. \& Ekman, R. (1987). Are gut peptides responsible for the Irritable Bowel Syndrome (IBS)? Scandinavian Journal of Gastroenterology Suppl. 130, 15-20.

Sjölund, K., Ekman, R., Lindgren, S. \& Rehfeld, J. F. (1996). Disturbed motilin and cholecystokinin release in the Irritable Bowel Syndrome. Scandinavian Joumal of Gastroenterology 31, 1110-1114.

Small, P. K., Loudon, A., Hau, C. M., Noor, N. \& Campbell, F. C. (1997). Large-scale ambulatory study of postprandial jejunal motility in Irritable Bowel Syndrome. Scandinavian Joumal of Gastroenterology 32, $39-47$.

Smith, M. A., Youngs, G. R., Barnes, R. M. R. \& Finn, R. (1985a). Food intolerance and atopic status in the Irritable Bowel Syndrome (IBS). Gut 26, A572.

Smith, M. A., Youngs, G. R. \& Finn, R. (1985b). Food intolerance, atopy and Irritable Bowel Syndrome. Lancet ii, 1064.

Snape, W. J., Matarazzo, S. A. \& Cohen, S. (1978). Effect of eating and gastrointestinal hormones on human colonic myoelectrical and motor activity. Gastroenterology 75, 373-378.

Snape, W. J., Wright, S. H., Battle, W. M. \& Cohen, S. (1979). The gastrocolic response: evidence for a neural mechanism. Gastroenterology 77, 1235-1240.

Song, J. Y., Merskey, H., Sullivan, S. \& Noh, S. (1993). Anxiety and depression in patients with abdominal bloating. Canadian Journal of Psychiatry 38, 475-478.

Spiller, R. C. (1994). Irritable bowel or irritable mind? Medical treatment works for those with clear diagnosis. British Medical Joumal 309, 1646-1647.

Spiller, R. C. (1997). Postinfective bowel dysfunction. Current Opinion in Gastroenterology 13, 85-89.

Steptoe, A. Wardle, J., Pollard, T. M., Canaan, L. \& Davies, G. J. (1996). Stress, social support and health-related behavior: a study of smoking, alcohol consumption and physical exercise. Journal of Psychosomatic Research 41 , $171-180$.

Sullivan, G., Blewett, A. E., Jenkins, P. L. \& Allison, M. C. (1997). Eating attitudes and the Irritable Bowel Syndrome. General Hospital Psychiatry 9, 62-64.

Sullivan, M. A., Cohen, M. D. \& Snape, W. J. (1978). Colonic myoelectrical activity in Irritable Bowel Syndrome. New England Journal of Medicine 298, 878-883.

Talley, N. J., Boyce, P. \& Owen, B. K. (1995a). Psychological distress and seasonal symptom changes in irritable bowel syndrome. American Journal of Gastroenterology 90, 2115-2119.

Talley, N. J., Weaver, A. L., Zinsmeister, A. R. \& Melton, L. J. (1992). Onset and disappearance of gastrointestinal symptoms and functional gastrointestinal disorders. American Journal of Epidemiology 136, 165-177.

Talley, N. J., Zinsmeister, A. R. \& Melton, L. J. (1995b). Irritable Bowel Syndrome in a community: symptom subgroups, risk factors and health care utilization. American Joumal of Epidemiology 142, 76-83.

Tamm, A. (1994). Management of lactose intolerance. Scandinavian Joumal of Gastroenterology Suppl. 202, 55-63.

Thompson, D. G., Richelson, E. \& Malagelada, J.-R. (1983). Perturbation of upper gastrointestinal function by cold stress. Gut 24, 277-283.

Thompson, D. G., Wingate, D. L., Archer, L., Benson, M. J., Green, W. J. \& Hardy, R. J. (1980). Normal patterns of huan upper small bowel motor activity recorded by prolonged radiotelemetry. Gut 21, 500-506.

Thompson, W. G. (1989). In Gut Reactions: understanding symptoms of the digestive tract, pp. 42-51 [W.G. Thompson, editor]. New York: Plenum.

Thompson, W.G. (1993). Irritable bowel syndrome-pathogenesis and management. Lancet 341, $1569-1572$.

Thompson, W.G., Creed, F., Drossman, D.A., Heaton, K.W. \& Mazzacca, G. (1992). Functional bowel disease and functional abdominal pain. Gastroenterology International 102, 1962-1967.

Thompson, W. G., Dotteval, G., Drossman, D. A., Heaton, K. W. \& Kruis, W. (1989). Irritable Bowel Syndrome, guidelines for the diagnosis. Gastroenterology International 2, 92-95.

Thompson, W. G. \& Gick, M. (1996). Irritable bowel syndrome. Seminars in Gastrointestinal Disease 7, $217-229$.

Thompson, W.G. \& Heaton, K.W. (1980).Functional bowel disorders in apparently healthy people. Gastroenterology 79, 283-288.

Thompson, W. G., Heaton, K. W., Smyth, G. T. \& Smyth, C. (1997). Imitable Bowel Syndrome: the view from general practice. European Journal of Gastroenterology and Hepatology 9, 689-692.

Tolliver, B. A., Jackson, M. S., Jackson, K. LO., Barnett, E. D., Chastang, J. F. \& DiPalma, J. A. (1996). Does lactose intolerance really play a role in the irritable bowel? Joumal of Clinical Gastroenterology 23, 15-17. 
Treem, W. R., Ahsan, N., Kastoff, G. \& Hyams, J. S. (1996). Fecal short-chain fatty acids in patients with diarrheapredominant Irritable Bowel Syndrome: in vitro studies of carbohydrate fermentation. Journal of Pediatric Gastroenterology and Nutrition 23, 280-286.

Trotman, I. F. \& Misiewicz, J. J. (1988). Sigmoid motility in diverticular disease and the irritable bowel syndrome. Gut 29, 218-222.

Trowell, H. (1974). Fibre and irritable bowels. British Medical Journal iii, 44.

Truswell, A. S. (1985). Food sensitivity. British Medical Journal 291, 951-955.

Van Dulmen, A. M., Fennis, J. F. M., Mokkink, H. G. A., Van Der Velden, H. G. M. \& Bleijenberg, G. (1997). Persisting improvement in complaint related cognitions initiated during medical consultation in functional abdominal complaints. Psychological Medicine 27, 725-729.

Vassallo, M. J., Camilleri, M., Phillips, S. F., Steadman, C. J., Talley, N. J., Hanson, R. B. \& Haddad, A. C. (1992). Colonic tone and motility in patients with Irritable Bowel Syndrome. Mayo Clinic Proceedings 67, 725-731.

Vatn, M. H. (1997). Food intolerance and psychosomatic experience. Scandinavian Journal of Work, Environment and Health 23, 75-78.

Veale, D., Kavanagh, G., Fielding, J. F. \& Fitzgerald, O. (1991). Primary Fibromyalgia and the irritable bowel syndrome. British Journal of Rheumatology 30, 220-222.

Verhaak, P. F. M. (1995). Determinants of the help-seeking process: Goldberg and Huxley's first level and first filter. Psychosomatic Medicine 25, 95-104.

Vernia, P., Ricciardi, M. R, Frandina, C., Bilotta, T. \& Frieri, G. (1995). Lactose malabsorption and Irritable Bowe] Syndrome: effect of a long-term lactose free diet. Italian Joumal of Gastroenterology 27, 117-121.

Vesa, T. M., Seppo, L. M., Marteau, P. R., Sahi, T. \& Korpela, R. (1998). Role of irritable bowel syndrome in subjective lactose intolerance. American Joumal of Clinical Nutrition 67, 710-715.

Vlitos. A. L. P. \& Davies, G. J. (1996). Bowel function, food intake and the menstrual cycle. Nutrition Research Reviews 9, 111-134.

Walker, E. A., Roy-Byrne, P. P., Katon, W., Li, L., Amos, D. \& Jiranek, G. (1990). Psychiatric illness and irritable bowel syndrome: a comparison with inflammatory bowel disease. American Journal of Psychiatry 147, $1656-1660$.

Wangel, A. G. \& Deller, D. J. (1965). Intestinal motility in man. III. Mechanisms of constipation and diarrhoea with particular reference to the Irritable Colon Syndrome. Gastroenterology 48, 69-84.

Weinstein, S. E., Shide, D. J. \& Rolls, B. J. (1997). Changes in food intake in response to stress in men and women: psychological factors. Appetite 28, 7-18.

Welgan, P., Meshkinpour, H. \& Beeler, M. (1988). Effect of anger on colon motor and myoelectric activity in the Irritable Bowel Syndrome. Gastroenterology 94, 1150-1156.

Whitehead, W. E., Bosmajian, L., Zonderman, A. B., Costa, P. T. \& Schuster, M. M. (1988). Symptoms of psychologic distress associated with Irritable Bowel Syndrome. Comparison of community and medical clinic samples. Gastroenterology 95, 709-714.

Whitehead, W. E., Burnett, C. K., Cook, E. W. \& Taub, E. (1996). Impact of Irritable Bowel Syndrome on quality of life. Digestive Diseases and Sciences 41, 2248-2253.

Whitehead, W.E., Winget, C., Fedoravicius, A.S., Wooley, S. \& Blackwell, B. (1982). Learned illness behaviour in patients with irritable bowel syndrome and peptic ulcer. Digestive Diseases and Sciences 27, 202-208.

Woodman, C. L., Breen, K., Noyes, R., Moss, C., Fagerholm, R., Yagla, S. J. \& Summers, R. (1998). The relationship between irritable bowel syndrome and psychiatric illness. A family study. Psychosomatics 39, $45-54$.

World Health Organization (1987). Joint Expert Committee on Food Additives. Toxicological Evaluation of Cenain Food Additives and contaminants (WHO Food Additives Series no. 21). Geneva: WHO.

Wright, S. H., Snape, W. J., Battle, W., Cohen, S. \& London, R. L. (1980). Effect of dietary components on gastrocolonic response. American Journal of Physiology 238, 228-232.

Wyatt, G. M., Bayliss, C. E., Lakey, A. F., Bradley, H. K., Hunter, J. O. \& Jones, V. A. (1988). The faecal flora of two patients with food-related Irritable Bowel Syndrome during challenge with symptom-provoking foods. Joumal of Medical Microbiology 26, 295-299.

Young, E., Stoneham, M. D., Petruckevitch, A., Barton, J. \& Rona, R. (1994). A population study of food intolerance. Lancet 343, 1127-1129.

Zaubler, T. S. \& Katon, W. (1996). Panic disorder and medical comorbidity: a review of the medical and psychiatric literature. Bulletin of the Menninger Clinic 60, A12-A38.

Zonderman, A. B., Heft, M. W. \& Costa, P. T. (1985). Does the Illness Behavior Questionnaire measure abnormal illness behavior? Health Psychology 4, 425-436.

Zwetchkenbaum, J. \& Burakoff, R. (1988a). The Irritable Bowel Syndrome and food hypersensitivity. Annals of Allergy $61,47-49$.

Zwetchkenbaum, J. F. \& Burakoff, R. (1988b). Food allergy and the irritable bowel syndrome. American Journal of Gastroenterology 83, 901-904. 